\title{
INDÍGENAS URBANOS Y DERECHOS CULTURALES: LOS LÍMITES DEL MULTICULTURALISMO LIBERAL
}

\author{
Daniel Bonilla Maldonado 1 \\ URBAN INDIANS AND CULTURAL RIGHTS: \\ THE LIMITS OF MULTICULTURAL LIBERALISM
}

\section{RESUMO}

En este artículo se eVAlúan los límites del MULTICULTURALISMO LIBERAL PARA DESCRIBIR Y EVALUAR LA REALIDAD DE LOS INDÍGENAS CONTEMPORÁNEOS. EL LIBERALISMO MULTICULTURAL LLENA DE CONTENIDO LA IDENTIDAD INDÍGENA HACIENDO USO DE LAS SIGUIENTES CINCO CATEGORÍAS: TERRITORIO ANCESTRAL, TERRITORIO RURAL, NATURALEZA SALVAJE, PRÁCTICAS CULTURALES ATÁVICAS Y ECONOMÍA DE SUBSISTENCIA. ESTA FORMA DE ENTENDER LA IDENTIDAD INDÍGENA, ADEMÁS, ES LA BASE PARA SUSTENTAR QUIÉNES SON TITULARES LEGÍTIMOS DE LOS DERECHOS CULTURALES COMPATIBLES CON EL LIBERALISMO. SIN EMBARGO, ESTA DESCRIPCIÓN DE LA IDENTIDAD INDÍGENA CHOCA CON LA REALIDAD DE BUENA PARTE DE LOS INDÍGENAS CONTEMPORÁNEOS. LA REALIDAD DE UNA PARTE MUY IMPORTANTE DE ESTOS INDIVIDUOS Y COLECTIVIDADES ESTÁ ESTRECHAMENTE RELACIONADA CON CONTEXTOS URBANOS QUE ESTÁN FUERA DE SUS TERRITORIOS ANCESTRALES. EN MÉxICO, POR EJEMPLO, APROXIMADAMENTE EL $30 \%$ DE LOS INDÍGENAS VIVE EN CIUDADES, EN CANADÁ LO HACE EL $50 \%$ y en Australia el 75\%. Hoy en día, EL 61\% DE LOS INDÍGENAS ESTADOUNIDENSES Y EL 21\% DE LOS COLOMBIANOS HABITAN EN ZONAS URBANAS. LOS INDÍGENAS CONTEMPORÁNEOS SON, EN BUENA PARTE, INDÍGENAS URBANOS QUE FORMAN PARTE DE LA ECONOMÍA dE MERCADO. No OBSTANTE, EL LIBERALISMO MULTICULTURAL, CON SUS CATEGORÍAS DESCRIPTIVAS Y NORMATIVAS, NO TIENE LA POSIBILIDAD DE RECONOCERLOS Y ACOMODARLOS APROPIADAMENTE EN LA COMUNIDAD POLÍTICA.

\section{PALAVRAS-CHAVE}

Multiculturalismo; LIBERALISMO; INDÍGENAS; IDENTIDAD.

\begin{abstract}
IN THIS ARTICLE, I ASSESS THE LIMITS OF LIBERAL MULTICULTURALISM TO DESCRIBE AND EVALUATE THE REALITY OF CONTEMPORARY INDIANS. LIBERAL MULTICULTURALISM STRUCTURES INDIAN IDENTITY APPEALING TO THE FOLLOWING FIVE CATEGORIES: ANCESTRAL TERRITORY, RURAL TERRITORY, WILD NATURE, ATAVIC CULTURAL PRACTICES, AND SUBSISTENCE ECONOMY. THIS WAY OF UNDERSTANDING INDIAN IDENTITY, MOREOVER, IS THE BASIS TO JUSTIFY WHO IS ENTITLED TO THE CULTURAL RIGHTS THAT ARE COMPATIBLE WITH LIBERALISM. HOWEVER, THIS DESCRIPTION OF INDIAN IDENTITY COLLIDES WITH THE REALITY OF A GREAT NUMBER OF CONTEMPORARY INDIANS. THE LIFE OF AN IMPORTANT PART OF THESE INDIVIDUALS AND GROUPS IS CLOSELY LINKED TO URBAN CONTEXTS THAT ARE OUTSIDE THEIR ANCESTRAL TERRITORIES. IN MEXICO, FOR EXAMPLE, APPROXIMATELY 30\% OF INDIANS LIVE IN CITIES, IN CANADA 50\%, AND IN AUSTRALIA 75\% DO SO. TODAY, $61 \%$ OF U.S. INDIANS AND $21 \%$ OF COLOMBIAN INDIANS LIVE IN URBAN AREAS. CONTEMPORARY INDIANS ARE IN GREAT PART URBAN INDIANS THAT ARE PART OF THE MARKET ECONOMY. YET, MULTICULTURAL LIBERALISM, ITS DESCRIPTIVE AND NORMATIVE CATEGORIES, DOES NOT HAVE THE CAPACITY TO RECOGNIZE AND ACCOMMODATE THEM PROPERLY TO THE POLITY.

\section{KEYWORDS}

MULTICULTURALISM; LIBERALISM; INDIANS; IDENTITY.
\end{abstract}


"There are strangers above me, below me and all around me and we are all strange in this place of recent invention. This city named for angels appears naked and stripped of anything resembling the shaking of turtle shells, the songs of human voices on a summer night outside Okmulgee. Yet, it's perpetually summer here, and beautiful. The shimmer of gods is easier to perceive at sunrise or dusk, when those who remember us here in the illusion of the marketplace turn toward the changing of the sun and say our names. We matter to somebody, We must matter to the strange god who imagines us as we revolve together in the dark sky on the path to the Milky Way. We can't easily see that starry road from the perspective of the crossing of boulevards, can't hear it in the whine of civilization or taste the minerals of planets in hamburgers. But we can buy a map here of the stars' homes, dial a tone for dangerous love, choose from several brands of water, or a hiss of oxygen for gentle rejuvenation. Everyone knows you can't buy love but you can still sell your soul for less than a song, to a stranger who will sell it to someone else for a profit until you're owned by a company of strangers in the city of the strange and getting stranger.

I'd rather understand how to sing from a crow who was never good at singing or much of anything but finding gold in the trash of humans. So what are we doing here I ask the crow parading on the ledge of falling that hangs over this precarious city? Crow just laughs and says wait, wait and see and I am waiting and not seeing anything, not just yet. But like crow I collect the shine of anything beautiful I can find"2 .

"I got them reservation blues I'm dressed up like a dude In my high heeled shoes I got my Visa and pay my dues I left my family back on the res big city lights I miss my family and kids been gone so long I don't know who I is"3

El poema de Joy Harjo y la canción de Charlie Hill, recogen uno de los núcleos que constituyen la experiencia actual de los indígenas urbanos. Las vivencias de buena parte de los indígenas que habitan en las ciudades de los Estados contemporáneos giran en torno a preguntas sobre los contornos y la estructura de su identidad individual y colectiva. Los personajes de estos escritos se preguntan quiénes son, qué variables los caracterizan y qué elementos constituyen la comunidad a la que pertenecen. Estos sujetos habitan un espacio que no es el que históricamente se asocia con el tipo de sujeto con el que ellos se identifican. Los indígenas, se dice tradicionalmente, no viven en las ciudades; los indígenas viven en el campo, en las reservas y resguardos; en sus territorios colectivos y ancestrales. Es en estos espacios donde su cultura se encuentra enraizada. Ahí están los referentes materiales y simbólicos que nutren sus tradiciones. Ahí y sólo ahí se pueden volver realidad las prácticas que los hacen sujetos y grupos particulares. Los indígenas son culturalmente diversos, se 
argumenta, dada la íntima relación que tienen con sus tierras ancestrales y con las variables físicas que las caracterizan. Los indígenas, se dice continuamente, tienen una relación particular y única con la naturaleza. Se entienden como parte del entorno natural, no como sus dueños. Su relación con la tierra no está, por tanto, centrada en su explotación.

En contraste, los personajes de Harjo y Hill, que se autodescriben como indígenas, viven en la ciudad, inmersos en la economía de mercado y con contactos físicos tenues con sus comunidades y culturas. Estos individuos, en última instancia, se preguntan si pueden llamarse legítimamente indígenas y vivir en la ciudad, si se puede hablar con sentido de ser "indígenas urbanos". La noción dominante sobre la identidad indígena, que ellos mismos han interiorizado, choca con los contextos en los que habitan, con muchas de las prácticas culturales que adelantan y con la manera como se comprenden.

Las preguntas que se hacen los protagonistas de estas narraciones son existenciales. Tienen que ver con el sentido y valor que tiene su proyecto de buen vivir y, por tanto, con el sentido y valor de su identidad individual. Sin embargo, estas mismas preguntas resultan fundamentales para el derecho y la filosofía política contemporáneos. El modelo liberal multicultural que fundamenta los derechos culturales o derechos diferenciados que se le han reconocido a las comunidades indígenas en democracias liberales tan distintas como Estados Unidos, Canadá, Brasil y Colombia, se basa en la existencia de un "otro" claramente distinguible. Sólo aquél que es culturalmente diverso puede ser titular de un conjunto de derechos que están fuera del alcance de los miembros de la cultura mayoritaria. Estos derechos (culturales, de autogobierno y de representación política grupal ${ }^{4}$, entre otros), son instrumentos que permiten a las minorías culturales proteger y reproducir sus tradiciones.

En el caso de las comunidades indígenas, el liberalismo multicultural se ha nutrido de un modelo antropológico según el cual ser "otro", históricamente, ha significado pertenecer a una minoría nacional; esto es, formar parte de una colectividad que habita un territorio ancestral, habla un idioma particular, encarna una cultura específica, tiene un pasado común y quiere mantenerse como una comunidad cultural distinta a la mayoritaria ${ }^{5}$. Esta asociación entre las comunidades indígenas y las minorías nacionales, usualmente, ha estado ligada a una descripción esencialista y homogeneizante de tales colectividades. Dicha descripción asocia estrechamente identidad con territorio, equipara territorio con tierras ancestrales rurales y relaciona íntimamente estas tierras con prácticas culturales tradicionales ${ }^{6}$. Así, el modelo liberal se nutre de un modelo antropológico, que en adelante llamaré “indigenista”, en el que lo indígena se asocia con las siguientes cinco categorías: territorio ancestral ${ }^{7}$, territorio rural, naturaleza salvaje, prácticas culturales atávicas y economía de subsistencia ${ }^{8}$.

Sin embargo, este modelo antropológico choca con la realidad de un número importante de personas que se autodescriben como indígenas pero que viven en 
contextos urbanos ${ }^{9}$, forman parte de la economía de mercado, no hablan o no dominan suficientemente el idioma tradicional de su comunidad, no ponen en práctica o no conocen la mayor parte de las tradiciones de sus ancestros y no tienen contacto con el territorio de su colectividad o solo interactúan esporádicamente con él. La existencia de indígenas urbanos es un fenómeno global. Así, por ejemplo, en México aproximadamente el 30\% de los indígenas vive en ciudades ${ }^{10}$, en Canadá lo hace el $50 \%{ }^{11}$ y en Australia el 75\%12. En Nueva Zelanda el 83\% de los Maoríes vive en contextos urba$\operatorname{nos}^{13}$ y de los 734.127 indígenas que viven en Brasil, 383.298 viven en áreas urbanas $^{14}$. En Chile, el 69,4\% de quienes se reconocen como indígenas vive en pueblos y ciudades y, de este grupo, el 27,1\% vive en Santiago ${ }^{15}$. Hoy en día, el 61\% de los indígenas estadounidenses ${ }^{16}$ y el $21 \%$ de los colombianos ${ }^{17}$ no habita en sus territorios ancestrales sino en contextos urbanos como Denver y Bogotá18. En Denver habitan $42.423^{19}$ indígenas mientras que en Bogotá lo hacen $15.033^{20}$.

En Denver y Bogotá, como en muchas otras ciudades del mundo, las preguntas y respuestas relacionadas con el modo en qué se debe acomodar y reconocer la diversidad cultural están directamente conectadas con los retos teóricos y prácticos que plantea la existencia de indígenas urbanos. Este escrito, en consecuencia, tiene como objetivo examinar los límites de estas categorías. En particular, busca evaluar las tensiones que existen entre el modelo liberal multicultural, que justifica los derechos diferenciados en muchas de las democracias liberales contemporáneas, y el modelo antropológico indigenista, del que aquel se nutre para calificar como un "otro" que es titular de derechos diferenciados a las comunidades indígenas, por un lado, y la existencia de indígenas urbanos, por el otro. La tesis central del artículo está compuesta por tres argumentos que se interrelacionan estrechamente.

En primera instancia, argumento que el modelo antropológico indigenista que usualmente nutre el derecho y la política liberal multicultural esencializa y homogeneiza las comunidades indígenas. Este modelo, por tanto, es incapaz de dar cuenta de la diversidad que existe dentro de estas colectividades y del carácter contingente de la identidad indígena. En tanto que el modelo identifica como componentes necesarios de una verdadera identidad indígena la existencia de un territorio ancestral rural e indómito y una cultura tradicional estrechamente ligada y dependiente de este territorio, es incapaz de describir una buena parte de los sujetos y comunidades que se autodescriben como indígenas pero que no satisfacen los anteriores requisitos para poder pertenecer "legítimamente" a una comunidad indígena, esto es, los indígenas urbanos.

En segunda instancia, argumento que los procesos masivos de urbanización de los indígenas, que se pueden ver tanto en el Sur como en el Norte Global, han hecho que las categorías más comúnmente aceptadas en la literatura filosófica liberal para nombrar los grupos culturales minoritarios (minoría nacional y grupo étnico ${ }^{21}$ ) resulten limitadas para designar la realidad de los indígenas urbanos - que, como se 
ha visto, constituyen un número importante de los individuos y colectividades que se definen como indígenas. Las comunidades indígenas no son siempre colectividades que viven en un territorio ancestral, con una historia, una lengua y una cultura comunes y que quieren mantenerse como una cultura claramente distinta y separada de la mayoritaria. Del mismo modo, las comunidades indígenas usualmente no están conformadas por grupos de inmigrantes voluntarios que quieren integrarse a las prácticas políticas de la cultura mayoritaria y que, a su vez, quieren mantener espacios privados y públicos para manifestar y reproducir su diferencia cultural. Los indígenas urbanos parecería que se sitúan en varios puntos intermedios en el rango creado por estas dos categorías.

En tercera y última instancia, quisiera argumentar que cuando se reconoce la existencia de indígenas urbanos se pierde el balance teórico y práctico logrado entre el modelo liberal multicultural y el modelo antropológico dominante que ha permitido justificar la existencia de derechos culturales para las comunidades indígenas. Esta dificultad teórica y práctica es consecuencia de la imposibilidad de describir a las comunidades indígenas urbanas como minorías nacionales. En particular, este hecho impide que el modelo liberal multicultural pueda aceptar que las comunidades indígenas urbanas sean titulares de derechos de autogobierno o de representación política grupal - derechos que han sido históricamente útiles para la defensa de las culturas tradicionales de las comunidades indígenas y que se han conseguido a través de largos y difíciles procesos en los que los indígenas han jugado un papel central y por los que han pagado un alto precio político y social.

Para fundamentar los anteriores argumentos dividiré este texto en dos partes. En la primera, presentaré los ejes que estructuran el modelo liberal multicultural que justifica los derechos diferenciados que muchos de los ordenamientos jurídicos de las democracias liberales contemporáneas reconocen a las comunidades indígenas, así como el modelo antropológico con el que está estrecha, pero contingentemente, ligado. De igual forma, en esta primera parte del texto haré explícita la manera como el derecho internacional y los ordenamientos jurídicos de las democracias liberales que reconocen derechos diferenciados a las comunidades indígenas se ven influenciados por la alianza entre el liberalismo multicultural y el modelo antropológico indigenista. En la segunda parte, analizaré los retos teóricos y prácticos que genera la existencia de indígenas urbanos para la defensa de los intereses de muchas comunidades indígenas, así como para los ordenamientos jurídicos y políticos comprometidos con el liberalismo multicultural.

\section{EL LIBERALISMO MULTICULTURAL Y EL MODELO ANTROPOLÓGICO INDIGENISTA}

El liberalismo multicultural, quisiera argumentar, es la vertiente teórica que considera que los derechos diferenciados son compatibles con la igualdad y la autonomía 22 . 
Esta interpretación del liberalismo defiende la idea de que la cultura es un bien que la comunidad política debe proteger y que, para conseguir este fin, es necesario que las minorías culturales sean titulares de un conjunto de derechos particulares de los que no son titulares los miembros de la cultura mayoritaria. ${ }^{23}$

Para esta corriente liberal, la cultura es un bien social o un bien primario ${ }^{24}$ necesario para el ejercicio de la autonomía. Los individuos no escogen, transforman o cambian sus proyectos de buen vivir en el vacío. Lo hacen dentro de un contexto cultural que determina las opciones disponibles para el sujeto, así como el valor que cada una de alternativas tiene. Los sujetos, se argumenta, no son mónadas que pueden construirse solitariamente, aisladas del "otro" y del entramado de variables y fuerzas que constituye la cultura en la que están inmersos.

Así, por ejemplo, un miembro de la comunidad indígena Nukak Maku, colectividad nómada que habita en la Amazonía colombiana, está sumido en un horizonte de perspectivas que le ofrece un número amplio pero limitado de opciones de buen vivir, por ejemplo, el ser cazador, pescador, recolector o médico tradicional (o una combinación de algunas de ellas) en zonas de selva húmeda tropical. Sin embargo, no le ofrece como una opción o como una alternativa valiosa el convertirse en un agricultor sedentario o en un comerciante que vive en una de las ciudades de la zona andina de Colombia. Claro, el contexto en el que viven los Nukak Maku puede variar. De hecho, algunos de los grupos que componen esta comunidad han entrado en contacto con la sociedad mayoritaria atraídos por las comodidades de la sociedad moderna, en busca de servicios médicos para sus miembros o huyendo de la violencia generada por el narcotráfico o el conflicto armado que vive Colombia. Este contacto ha hecho que algunos de estos indígenas se hayan asentado en contextos urbanos, hayan aprendido español o se hayan distanciado de su cultura tradicional. En estos casos las opciones disponibles para el ejercicio de la autonomía individual de los Nukak Maku son diferentes a las de los grupos y sujetos que no han tenido contacto con la sociedad mayoritaria. Sin embargo, este sigue siendo el contexto dentro del cual los miembros de esta comunidad construyen y reconstruyen su identidad.

Ahora bien, las razones por las cuales los liberales multiculturales creen que la cultura debe protegerse varían. Para unos debe protegerse en tanto que constituye un bien primario para los individuos; para otros, en tanto que es un bien social que tiene valor en sí mismo ${ }^{25}$. En el primer caso, la cultura es un recurso necesario para que el sujeto pueda construir su identidad individual. Es un bien necesario para que cada uno pueda escoger y transformar su proyecto de buen vivir. La cultura no tiene valor en sí misma; lo tiene en tanto que es una herramienta necesaria para poder acceder a otros bienes que se consideran valiosos. En el segundo caso, la cultura tiene un valor social que es independiente de la función que cumple en relación con la autonomía individual. No es un bien sólo porque sea un medio para que las personas 
alcancen un fin que consideran valioso - ejercer su autonomía. La cultura tiene un valor intrínseco en tanto que es la condición de posibilidad de las cosas que los individuos valoran ${ }^{26}$. Sin tal entramado de perspectivas esas otras cosas que los individuos consideran valiosas no existirían.

A pesar de las diferencias que existen dentro del liberalismo multicultural sobre las razones que justifican que la cultura sea considerada un bien, existe un amplio acuerdo dentro de esta perspectiva teórica en torno a que las minorías culturales deben ser titulares de una serie de derechos que les permitan defender y promover sus tradiciones. Las minorías culturales han de tener herramientas jurídicas para evitar el decaimiento de su cultura. Admitir su declive o desaparición, afirma el liberalismo multicultural, debe ser una decisión de sus miembros y no una consecuencia de las relaciones de poder que existen dentro del Estado. Ciertamente, los miembros de las minorías culturales podrían ser asimilados por otra cultura y, por tanto, tener acceso a un horizonte de perspectivas particular - aunque tenga contornos y ejes distintos al de la cultura tradicional. Estos individuos podrían ejercer su autonomía dentro de este nuevo entramado cultural. Sin embargo, el costo que tendrían que pagar por este cambio es usualmente alto y no podría imponérseles justificadamente. El precio que pagarían en términos económicos y de autoestima, por ejemplo, sería excesivo.

Las consecuencias de la asimilación forzada de los indígenas en el continente americano evidencian el alto importe que pagan los individuos cuando cambian forzadamente de cultura. Las políticas de reasentamiento obligatorio en ciudades, por ejemplo, han causado daños tremendos entre los miembros de las comunidades indígenas. En la ciudad, las personas que tradicionalmente han vivido en contextos rurales, pierden los referentes que explican y dan valor a sus vidas. En una ciudad industrial que gira en torno a la economía de mercado, por ejemplo, un pescador que es socialmente estimado en la comunidad rural y lacustre de la que proviene pasa a ser un sujeto anónimo con muy poco valor en la colectividad. La autoestima, el capital social y los recursos económicos de este individuo disminuyen notablemente con el cambio de contextos culturales.

Ahora bien, para el liberalismo multicultural los derechos diferenciados no deben defenderse únicamente para proteger la autonomía individual. También han de protegerse por razones de igualdad. Las minorías culturales, usualmente, están en desventaja frente a las culturas mayoritarias en cuanto al poder que tienen para proteger y promover sus tradiciones. El Estado, generalmente, usa las enormes fuerzas de que dispone para proteger la cultura dominante dentro de la comunidad política. La acción estatal, por tanto, hace que las probabilidades de que la cultura de la sociedad mayoritaria pueda florecer y proyectarse en el futuro sean altas y que, en contraste, las probabilidades de que esto mismo suceda con las culturas de las comunidades minoritarias sean notablemente más bajas. Los derechos 
diferenciados, argumenta el liberalismo multicultural, son las herramientas jurídicas que permiten que las culturas minoritarias determinen autónomamente el tipo y grado de contacto que quieren tener con la cultura mayoritaria y se opongan efectivamente a las intervenciones indebidas del Estado en los asuntos privados y públicos de la comunidad.

Ahora bien, la defensa de los derechos diferenciados que hace el liberalismo multicultural choca de manera directa con la interpretación estándar del canon liberal. El liberalismo procedimental considera que la intervención del Estado en cuestiones relacionadas con la cultura es una violación de principios centrales del liberalismo. Por un lado, viola el principio que indica que el Estado debe respetar la frontera que separa el ámbito de lo privado del ámbito de lo público ${ }^{27}$. El primero es el espacio de la moral; la esfera en donde los individuos articulan, transforman e intentan materializar sus proyectos de buen vivir. Este, por tanto, es el espacio de la cultura categoría que está directamente relacionada con las opciones vitales que escogen las personas. Cuestiones que tienen que ver con la religión que se profesa, los idiomas que se hablan o las prácticas sociales con las que se está comprometido, por ejemplo, competen únicamente a los individuos; están estrechamente ligados con el tipo de sujeto que quieren hacer de sí mismos.

El segundo es la esfera de la justicia; la órbita en donde se determina la estructura básica de la comunidad política y, por tanto, el lugar donde se decide cómo ha de distribuirse el poder, la autoridad y los recursos de los que ésta dispone. Las acciones estatales que cruzan los límites que protegen la autonomía de estas dos órbitas violentan el espacio que tienen los individuos para ejercer su autonomía y construir su identidad. El Estado, argumenta el liberalismo procedimental, no debe invadir el espacio íntimo en donde el sujeto se construye autónomamente. Para el liberalismo procedimental debe haber una discontinuidad entre la órbita privada y la órbita pública si se quiere proteger la libertad individual ${ }^{28}$.

Por otro lado, la intervención del Estado en cuestiones relacionadas con la cultura viola el principio que indica que éste debe tratar con igual consideración y respeto a todos los ciudadanos ${ }^{29}$. El Estado, señala el liberalismo procedimental, debe mantenerse neutral frente a los proyectos de buen vivir de sus asociados y, según afirma vehementemente esta doctrina, no puede poner al servicio de un proyecto de buen vivir, así sea el que las mayorías favorecen, los inmensos recursos materiales y simbólicos que tiene a su disposición. De hacerlo, estaría privilegiando a un grupo de miembros de la polis por sobre los otros y, por ende, estaría atentando contra la igualdad política de todos los asociados. De igual forma, estaría poniendo en cuestión la igualdad básica de todos los seres humanos, que justifica la igualdad política de los ciudadanos con la que está comprometido el liberalismo.

El liberalismo multicultural responde al liberalismo procedimental con dos argumentos. El primero, hace referencia a la estrecha conexión que existe entre la 
autonomía individual y la cultura a la que se aludió anteriormente. Agrega, además, que el liberalismo procedimental pierde de vista que los sujetos no escogen pertenecer a una cultura determinada; nacen en ella. La autonomía, por tanto, no tiene nada que ver con el horizonte de perspectivas dentro del cual está inmerso el sujeto al inicio y durante buena parte de su vida. Es evidente que, teóricamente, los sujetos pueden escoger cambiar de cultura. Sin embargo, los recursos materiales que la mayoría de las personas controlan no permiten que ésta sea una opción real la mayoría de las veces. Cuando lo es, tal como se manifestó más arriba, esta opción implica pagar unos costos que pocas personas estarían dispuesta a asumir.

El segundo argumento indica que el ideal de la neutralidad del Estado, en el que se basa el liberalismo procedimental, es irrealizable ${ }^{30}$. El Estado no puede dejar de tomar decisiones sobre cuestiones relacionadas con la cultura. Determinar cuál es el idioma oficial del Estado, cuáles son sus símbolos patrios y cómo se deben distribuir los recursos escasos para financiar las prácticas culturales de las personas y colectivos, son cuestiones que el Estado ineludiblemente debe decidir. Cuando esta dimensión de la realidad política se deja al margen, apelando al ideal de la neutralidad, usualmente se oscurece el hecho de que el Estado ha tomado y seguirá tomando este tipo de decisiones de manera que favorezcan al proyecto moral de las mayorías. Los derechos diferenciados, según argumenta el liberalismo multicultural, son las herramientas que permiten que las minorías culturales tengan tantas probabilidades de proteger y promover sus tradiciones como las que tiene la cultura mayoritaria.

Ahora bien, los derechos diferenciados defendidos por el liberalismo multicultural son de distinto tipo. Dependen del bien que buscan proteger y de las características de la minoría cultural que va a ser protegida. En primera instancia, están los derechos de autogobierno ${ }^{31}$. Estos derechos permiten que las minorías culturales decidan autónomamente los asuntos políticos y jurídicos de la comunidad. Cuestiones como la creación de una jurisdicción indígena que permita juzgar a los miembros de la colectividad, decidir la manera como se explotan los recursos naturales que existen dentro de los territorios indígenas y precisar los criterios para asignar las tierras colectivas entre los miembros de la comunidad, son posibles únicamente si estas colectividades son titulares de derechos de autogobierno.

En segunda instancia están los derechos de representación política grupal. Estos derechos permiten que las minorías culturales puedan participar en los procesos de toma decisión política en el Estado al que pertenecen. Si estos derechos no existieran, el desequilibrio de poder político y económico que existe entre la cultura mayoritaria y las minoritarias haría muy poco probable, si no imposible, que los representantes de éstas últimas pudieran acceder a los espacios políticos nacionales. Los derechos de representación política grupal justificarían, por ejemplo, la creación de distritos electorales especiales para las minorías culturales o la creación de cupos para este tipo de colectividades en las juntas directivas de las agencias estatales 
encargadas de diseñar las políticas que determinan los contornos y características de las relaciones interculturales.

En tercera instancia, están los derechos culturales que permiten la defensa y promoción de las tradiciones culturales. Estos derechos justificarían la creación de programas de etnoeducación, la financiación de centros culturales y festivales que permitan la difusión y reproducción de las tradiciones culturales de las minorías, y la promoción de publicaciones oficiales que muestren las contribuciones que han hecho a la comunidad política los grupos minoritarios.

Ahora bien, como se verá a continuación, estos tres tipos de derechos, y sus justificaciones, usualmente aparecen de la mano del modelo antropológico indigenista que esencializa y homogeneiza las comunidades indígenas.

\section{EL MODELO ANTROPOLÓGICO INDIGENISTA}

El liberalismo multicultural usualmente se nutre del modelo antropológico indigenista cuando se aproxima a los problemas, necesidades y retos de las comunidades indígenas. Este modelo llena de contenido la identidad indígena a partir de las siguientes categorías: territorio ancestral, territorio rural, naturaleza salvaje, prácticas culturales atávicas ineludiblemente relacionadas con el territorio, economía de subsistencia y pretensión de mantenerse como una comunidad cultural distinta de la comunidad cultural mayoritaria. Este modelo ha sido defendido, generalmente, tanto por las comunidades indígenas mismas como por individuos que pertenecen a la sociedad mayoritaria (políticos, antropólogos, abogados y sociólogos, por ejem$\mathrm{plo}^{32}$ ). Por consiguiente, este modelo permite calificar a las comunidades indígenas como minorías nacionales ${ }^{33} \mathrm{y}$, por tanto, justificar que éstas sean titulares de derechos diferenciados como los de autogobierno y de representación política grupal ${ }^{34}$.

Los líderes indígenas Seattle y Rojas Birry sintetizan en unas pocas líneas y de manera precisa el modelo antropológico indigenista. Al respecto señala el jefe Seattle, "Nuestra creencia espiritual es que fuimos creados como parte de la tierra - de esta forma, nuestra identidad, nuestros nombres, nuestras canciones están todas unidas a la tierra."35. Del mismo modo, el dirigente Embera Rojas Birry afirma: "Sin este derecho (propiedad colectiva) los anteriores (derechos a la identidad cultural y a la autonomía) son sólo reconocimientos formales. El grupo étnico requiere para sobrevivir del territorio en el cual está asentado, para desarrollar su cultura. Presupone el reconocimiento al derecho de propiedad sobre los territorios tradicionales ocupados y los que configuran su hábitat."36

Cuando se analizan estas citas, podemos ver que el modelo antropológico indigenista "territorializa”, “ecologiza” y esencializa la identidad indígena. Para este modelo, el verdadero indígena es aquel que vive en el territorio ancestral de su comunidad. En tanto que existe una conexión inexorable entre un territorio particular y las prácticas 
culturales que identifican a la comunidad como una entidad específica y distinta de las demás, el individuo no puede ser realmente un indígena fuera de las tierras históricas de su colectividad. Conocer y vivir en el territorio es un requisito para conocerse a sí mismo ${ }^{37}$. Aquel que se llama indígena y vive en las ciudades es sólo un indígena en términos formales, no sustanciales. Ser un indígena Arhuaco, por ejemplo, implica tener la posibilidad de tomar parte en ritos religiosos, como los pagamentos, que solo pueden tener lugar en ciertas montañas, ríos o lagunas de la Sierra Nevada de Santa Marta, en la costa Atlántica colombiana. Ser un indígena Kogi, para seguir con los ejemplos, implica estar a cargo de la protección de la madre tierra y del balance del universo. Este objetivo puede ser alcanzado en tanto que la comunidad habita la Sierra Nevada de Santa Marta, que es considerada por los Kogi como el ombligo del mundo. Sólo desde este macizo montañoso es posible mantener el equilibrio de la madre tierra. Ser un indígena Kogi y vivir en la ciudad, por ende, es una imposibilidad fáctica.

De esta manera, el modelo centra la identidad indígena no en el sujeto, ni en la descripción que éste hace de sí mismo, sino en la materialización de un hecho específico, esto es, habitar un territorio ancestral. El modelo no excluye que la descripción que hace el individuo de sí mismo o los lazos de sangre que tenga formen parte de los criterios que permiten identificar a un indígena. Sin embargo, sí defiende como criterio necesario y nuclear para lograr este fin, que se precise el domicilio del sujeto, y que éste coincida con las tierras atávicas de la comunidad a la que la persona dice pertenecer ${ }^{38}$. La identidad indígena, por tanto, no migra con el sujeto. Es una identidad estable e inmovible en tanto que se conecta directa e ineludiblemente con la tierra. Esta interpretación contrasta con las formas de comprender la identidad que se centran en la sangre o el reconocimiento y práctica de las reglas morales de la colectividad. La comunidad judía, por ejemplo, no exige que la persona viva en la tierra prometida para que pueda considerarse miembro de la colectividad. Basta que el individuo manifieste su compromiso con las normas morales que la regulan o que sus ascendientes sean parte de la comunidad para que el individuo sea considerado un miembro de la misma.

El modelo antropológico indigenista también afirma que un verdadero indígena es un individuo "ecológico" 39. Los indígenas, para este modelo, se distancian de una visión antropocéntrica de la naturaleza donde el ser humano es el eje del universo. Los hombres y mujeres, se argumenta, son parte integral de la creación y tienen una importancia relativa dentro de la misma ${ }^{40}$. Consecuentemente, la naturaleza no está subordinada a los seres humanos. La flora, la fauna y los minerales no son de su propiedad. La relación entre los indígenas y la tierra no es, ni debe ser, de explotación y destrucción ${ }^{41}$. Los indígenas, argumenta el modelo indigenista, tienen una visión holística del mundo. Las partes no pueden separarse del todo y cada parte juega un papel particular e importante en el Uno. De hecho, los indígenas 
antes que derechos sobre la naturaleza, como lo defiende la tradición judeocristiana, tienen obligaciones frente a la misma. Los indígenas deben proteger la naturaleza; contribuir a que se mantenga el balance entre todos los elementos que componen el universo ${ }^{42}$.

El modelo, en consecuencia, asocia las comunidades indígenas con tierras rurales y salvajes. El indígena es un individuo que está en contacto directo y cotidiano con una naturaleza que todavía no ha sido transformada por la mano del hombre ${ }^{43}$. Si lo ha sido, el deber de la comunidad indígena es hacer lo posible para que vuelva a su estado original. De esta forma, el modelo antropológico indigenista asocia las comunidades indígenas con economías de subsistencia ${ }^{44}$. La explotación de la naturaleza y la acumulación propias de la economía capitalista son, se argumenta, ajenas a los modos de vida de las comunidades indígenas ${ }^{45}$. La economía de mercado lleva usualmente al uso desmedido de los recursos naturales y, por ende, a su desaparición. Los indígenas, señala el modelo indigenista, sólo extraen los recursos naturales que son necesarios para su supervivencia. Los indígenas son agentes fundamentales para alcanzar la sostenibilidad de todas las especies y materias que habitan la tierra.

Finalmente, el modelo también esencializa la identidad indígena ${ }^{46}$. El ser indígena, presupone esta teoría, ha permanecido invariable a través de los tiempos. Parecería que las transformaciones que ha habido entre las condiciones en las que viven y los elementos que caracterizan a las comunidades indígenas actualmente, y las condiciones y peculiaridades de los indígenas prehispánicos son marginales. El núcleo de lo que significa ser indígena no ha mutado en los últimos 500 años ${ }^{47}$. Esto no quiere decir, por supuesto, que el modelo no describa apropiadamente las condiciones en las que viven algunas comunidades indígenas hoy en día. Ciertamente, algunas de estas colectividades habitan en territorios ancestrales rurales y sus prácticas culturales están estrechamente ligadas con esas tierras.

Sin embargo, el modelo pierde de vista la diversidad interna que hay dentro del mundo indígena ${ }^{48}$. Oscurece el hecho de que algunas de estas comunidades aunque viven en sus territorios ancestrales han perdido sus tradiciones culturales o las han mezclado con tradiciones de la sociedad mayoritaria; no hablan ya el idioma tradicional o solo algunos pocos mayores lo hacen; y han pasado a formar parte, con mayor o menor intensidad, de la economía de mercado ${ }^{49}$. De igual forma, no reconoce que un porcentaje notablemente alto de individuos que se autodescriben como indígenas viven en contextos urbanos, lejos de sus territorios ancestrales, se han integrado a la economía capitalista y tienen contactos tenues con las culturas de sus ancestros. El modelo antropológico indigenista que históricamente aparece junto al liberalismo multicultural para describir y otorgar derechos a las comunidades indígenas, en suma, es incapaz de dar cuenta de una parte importante de los indígenas contemporáneos. 


\section{El LiberAlismo MULTicULTURAL, EL MODELO ANTROPOLÓGICO INDIGENISTA Y EL DERECHO}

El derecho internacional y los ordenamientos jurídicos de muchas democracias liberales se han visto influenciados por la alianza entre el liberalismo multicultural y el modelo antropológico indigenista ${ }^{50}$. Es común encontrar que tanto las reglas como la jurisprudencia internacional y doméstica de un número importante de democracias liberales reconocen que la cultura es un bien que debe ser protegido. Más precisamente, que la cultura de las minorías debe serlo, dado el desbalance de poder que existe entre éstas y la cultura mayoritaria. Para alcanzar este fin, se argumenta en estos sistemas jurídico-políticos, es necesario que las comunidades indígenas sean titulares de un conjunto de derechos diferenciados, en particular, aquellos que son legítimamente otorgados a las minorías nacionales, como el derecho al autogobierno y a una participación política efectiva en los asuntos del Estado central o federal que las afectan directamente.

Así, por ejemplo, el artículo 27 del Pacto Internacional de Derechos Civiles y Políticos señala que, “[e]n los Estados en que existan minorías étnicas, religiosas o lingüísticas, no se negará a las personas que pertenezcan a dichas minorías el derecho que les corresponde, en común con los demás miembros de su grupo, a tener su propia vida cultural, a profesar y practicar su propia religión y a emplear su propio idioma”. La interpretación que hace las Naciones Unidas de esta norma señala, además, que el derecho a la cultura propia implica el reconocimiento de la autonomía que tienen las minorías culturales para determinar quién transita o se asienta en su territorio o para determinar el grado y tipo de contacto que quieren tener con otras culturas ${ }^{51}$.

De igual forma, el Convenio 169 de la OIT sobre Pueblos Indígenas y Tribales en Países Independientes señala en su artículo 4 que, "[d]eberán adoptarse las medidas especiales que se precisen para salvaguardar [...] las culturas y el medio ambiente de los pueblos interesados" ${ }^{2}$; en su artículo 6 afirma que las comunidades indígenas tienen derecho a la consulta previa ${ }^{53}$; y en su artículo 9 reconoce una forma de jurisdicción indígena en materia penal ${ }^{54}$. Del mismo modo, la sección segunda del Pacto, que lleva por título "Tierras", indica en el artículo 13 que, "[a]l aplicar las disposiciones de esta parte del Convenio, los gobiernos deberán respetar la importancia especial que para las culturas y valores espirituales de los pueblos interesados reviste su relación con las tierras o territorios, o con ambos, según los casos, que ocupan o utilizan de alguna otra manera y en particular los aspectos colectivos de esa relación”. Finalmente, esta sección del Pacto ordena a los países que forman parte del mismo que reconozcan a las comunidades indígenas el derecho a la propiedad de sus tierras ancestrales ${ }^{55}$, así como les ordena proteger el derecho que tienen estas colectividades a explotar los recursos naturales que se encuentran dentro de sus territorios ${ }^{56}$. 
La jurisprudencia de la Corte Interamericana de Derechos Humanos igualmente recoge los ejes que estructuran la alianza entre el liberalismo multicultural y el modelo antropológico indigenista. En tres sentencias centrales sobre los derechos de las comunidades indígenas, Awas Tingni vs. Nicaragua, Saramaka vs. Surinam y Moiwana vs. Surinam, la Corte enfatiza la relación íntima que existe entre cultura indígena y territorio ${ }^{57}$. En Awas Tingni la Corte señala,

"Entre los indígenas existe una tradición comunitaria sobre una forma comunal de la propiedad colectiva de la tierra, en el sentido de que la pertenencia de ésta no se centra en un individuo sino en el grupo y su comunidad. Los indígenas por el hecho de su propia existencia tienen derecho a vivir libremente en sus propios territorios; la estrecha relación que los indígenas mantienen con la tierra debe ser reconocida y comprendida como la base fundamental de sus culturas, su vida espiritual, su integridad, y su supervivencia económica. Para las comunidades indígenas la relación con la tierra no es meramente una cuestión de posesión y producción sino un elemento material y espiritual del que deben gozar plenamente, inclusive para preservar su legado cultural y transmitirlo a las generaciones futuras" 58 .

En Colombia, el liberalismo multicultural, en alianza con el modelo antropológico indigenista, nutre las normas que regulan las relaciones interculturales en la Constitución de 199159. En particular, el artículo 246, que concede a los pueblos aborígenes el derecho a ejercer facultades jurisdiccionales dentro de su territorio, y el Artículo 330, que reconoce el derecho de los grupos aborígenes a gobernarse a sí mismos según sus usos y costumbres 60 . De igual manera, esta alianza ha justificado la amplia línea jurisprudencial promulgada por la Corte Constitucional colombiana sobre los derechos territoriales y de autogobierno de las comunidades indígenas ${ }^{61}$. Al respecto, por ejemplo, dice la Corte Constitucional en la sentencia T-188/9362,

"El derecho de propiedad colectiva ejercido sobre los territorios indígenas reviste una importancia esencial para las culturas y valores espirituales de los pueblos aborígenes. Esta circunstancia es reconocida en convenios internacionales aprobados por el congreso (ley 21 de 1991 aprobatoria del Convenio 169 de la OIT aparece en cita que se omite), donde se resalta la especial relación de las comunidades indígenas con los territorios que ocupan, no sólo por ser éstos su principal medio de subsistencia sino, además, porque constituyen un elemento integrante de la cosmovisión y la religiosidad de los pueblos aborígenes. Adicionalmente, el constituyente resaltó la importancia fundamental del derecho al territorio de las comunidades indígenas" 63 . 
Finalmente, la asociación entre el liberalismo multicultural y el modelo antropológico indigenista también ha influenciado algunas normas jurídicas relacionadas con las comunidades indígenas estadounidenses ${ }^{64}$. Así, por ejemplo, el American Indian Religious Freedom Act obliga al gobierno a proteger las religiones tradicionales de las comunidades indígenas ${ }^{65}$; el National Historic Preservation Act ${ }^{66}$ permite que el gobierno federal proteja el legado cultural de las comunidades; y el Native American Graves Protection and Repatriation Act, ${ }^{67}$ determina los medios para precisar quién es dueño de los artefactos culturales que sean descubiertos en territorio de propiedad de las comunidades indígenas o del gobierno federal ${ }^{68}$.

Como puede verse, los ordenamientos jurídicos de las democracias liberales que reconocen derechos diferenciados a las comunidades indígenas entroncan de manera precisa con el liberalismo multicultural y el modelo antropológico indigenista. El primero, justifica su reconocimiento, provee las herramientas hermenéuticas para que las comunidades indígenas puedan ser titulares de derechos como los de autogobierno y representación política grupal, y, al mismo tiempo, asegura que el sistema político-jurídico mantenga su coherencia. Los derechos diferenciados, como se ha visto, son interpretados por el liberalismo multicultural de manera que sean consistentes con la autonomía individual y la igualdad.

El segundo, el modelo antropológico indigenista, dota al sistema jurídico de una definición clara y precisa del "otro" material que debe ser titular de los derechos diferenciados. Un concepto estático y estable de las comunidades indígenas permite proteger el carácter general y abstracto de las normas de un sistema jurídico liberal. Los derechos diferenciados de una categoría de individuos, los indígenas, y esta categoría de individuos permanece fija - lo que permite que las normas que les aplican tengan "vocación de eternidad", esto es, puedan ser eficaces por muy largos periodos de tiempo.

Para el derecho resulta fundamental que se garantice la estabilidad del sujeto de derechos. Variar los criterios para identificar los individuos que se reconocen como indígenas implica transformar las definiciones jurídicas existentes o crear excepciones o subcategorías de las mismas. Estos movimientos argumentativos generan retos importantes para la adecuada protección de valores centrales para el derecho liberal, como la igualdad, la eficacia y la seguridad jurídicas. Cuando el sistema jurídico liberal concede derechos diferenciados a las comunidades indígenas, está aceptando que un grupo de la comunidad política es el único titular de un conjunto de derechos. Por tanto, resulta fundamental que la categoría de individuos que pueden exigirlos sea clara, precisa y no admita usos estratégicos por parte de operadores que, aunque no cumplen con los requisitos formales para ser sus titulares, están interesados en acceder a los beneficios que generan. Los riesgos de violar principios centrales del concepto de justicia liberal, como la igualdad y la imparcialidad del Estado, saltan a la vista. 
No obstante, los costos que produce la estabilidad del sujeto de derechos diferenciados, que es común en los ordenamientos jurídicos de las democracias liberales contemporáneas, son también altos. Estos derechos son, en principio, inaplicables para las comunidades indígenas urbanas. La mayoría de las normas que regulan las relaciones entre estas minorías culturales y el Estado no podrían, por ende, generar ningún efecto entre buena parte de los individuos que se reconocen como indígenas. Puede ser que este conjunto de derechos ya no sirva para proteger los intereses de las comunidades indígenas. Es posible que algunas de estas comunidades piensen su relación con la cultura tradicional y con la sociedad mayoritaria de una manera distinta a como lo hacen los indígenas adecuadamente descritos por el modelo antropológico indigenista. El problema es, entonces, que aparentemente estos individuos son titulares sólo de los derechos ciudadanos liberales tradicionales (libertad de expresión y conciencia, por ejemplo) para proteger su diferencia. Sin embargo, parecería que los indígenas urbanos tienen reclamos legítimos que exigen un nivel de protección de su diversidad cultural mayor que la que pueden otorgar tales derechos. Los indígenas urbanos parecen estar a medio camino entre las minorías nacionales, que deben ser titulares de derechos de autogobierno y de representación política grupal, y los grupos étnicos, que deben ser titulares de derechos culturales que les permitan manifestar su diferencia dentro de la sociedad mayoritaria.

Ahora bien, resulta fundamental precisar que las categorías minoría nacional, grupo étnico, derechos de autogobierno, derechos políticos y derechos culturales son usadas comúnmente por el liberalismo multicultural como categorías descriptivas que pretenden, generalmente, nombrar las características, intereses y reclamos de las comunidades culturales que esta perspectiva considera como centrales en el mundo contemporáneo y los tipos de derechos culturales disponibles para defenderlos. Sin embargo, también resulta fundamental señalar que la conexión que hace el liberalismo multicultural entre la tipología de las comunidades culturales minoritarias que ofrece y los derechos que cada una de ellas podría reclamar tiene componentes normativos. Esta conexión explicita cuales son los derechos que las distintas minorías culturales, dadas sus características y aspiraciones, podrían exigir legítimamente.

Finalmente, es necesario precisar que en este texto se hace uso de estas categorías para evidenciar los límites descriptivos que tiene el liberalismo multicultural o, como se verá en el próximo apartado, para tender puentes normativos preliminares y tentativos entre los derechos diferenciados y la tipología de indígenas urbanos que se toma en consideración en este artículo. El uso que se hace de tales conceptos en este documento no implica ningún compromiso con otros argumentos normativos que defiende el multiculturalismo liberal, como, por ejemplo, la primacía inmediata e ineludible de los derechos individuales por sobre cualquier otro tipo de derecho o la idea de que los derechos culturales se pueden justificar adecuadamente únicamente cuando se apela a la libertad individual y la igualdad. 


\section{LA INVISIBILIDAD DE LOS INDÍGENAS URBANOS: RETOS TEÓRICOS Y PRÁCTICOS}

La alianza entre el liberalismo multicultural, el modelo antropológico indigenista y el derecho ha vuelto invisibiles y ha marginado a los indígenas urbanos. Como se ha visto a lo largo de este texto, este marco teórico-práctico, dentro del cual generalmente se entiende la cuestión indígena en las democracias liberales, es incapaz de dar cuenta de aquellos individuos y colectividades que se reconocen como indígenas y viven en contextos urbanos ${ }^{69}$. Ahora bien, la oscuridad en la que han sido mantenidos estos individuos y grupos como consecuencia de la hegemonía política de este conjunto de categorías conceptuales genera, a su vez, tres problemas importantes para la adecuada descripción, comprensión y evaluación de las comunidades indígenas contemporáneas.

En primera instancia, el modelo resulta cuestionable desde el punto de vista descriptivo. Este marco teórico opaca el hecho de que las comunidades indígenas vivieron y viven en ciudades y pueblos que en ocasiones han sido más grandes e importantes que las habitadas por los miembros de la actual sociedad mayoritaria. Forbes sintetiza este argumento de manera sugerente:

"la mayoría de los autores europeos imaginan a las comunidades indígenas americanas como pueblos que viven en el campo, en selvas, bosques, llanuras/pampas, o en pequeñas aldeas rodeadas de montañas en los Andes. Naturalmente, para ellos se vuelve problemático descubrir que un enorme número de comunidades indígenas residen actualmente en ciudades como Buenos Aires, Lima, La Paz, Quito, Ciudad de Guatemala, Ciudad de México, Toronto, Denver, Chicago, Los Ángeles, San Francisco-Oakland, y otras más. De lo que muchos autores no indígenas no se dan cuenta es que las comunidades indígenas americanas, de hecho, han pasado por periodos de desurbanización y reurbanización en varios momentos de su historia y que la vida urbana ha sido, desde hace mucho y desde tiempos antiguos, un aspecto importante de la vida en América. Bien puede ser que América viviera un proceso de desarrollo urbano mayor que el de cualquier otro continente en el periodo anterior al año $1500 \mathrm{dC}$, con el surgimiento de las ciudades más elaboradamente planeadas que se pudieran encontrar en cualquier parte del mundo" 70 .

De esta forma, el eje teórico conformado por el liberalismo multicultural, el modelo antropológico indigenista y el derecho de buena parte de las democracias liberales resulta cuestionable desde el punto de vista descriptivo. Al concentrarse excesivamente en el carácter rural de muchas de las comunidades indígenas, pierde de vista que un número considerable de estas comunidades construyeron o ayudaron a construir importantes asentamientos urbanos. Ciudades como Teotihuacan y Cuzco, en el pasado, o Denver y Bogotá, actualmente, no caben dentro de la imagen de lo 
auténticamente indígena que articula el eje teórico mencionado. Las ciudades indígenas o las urbes con población indígena no aparecen en la narración que este eje hace de la historia de las comunidades indígenas. La continuidad histórica que supuestamente existe entre las comunidades indígenas prehispánicas rurales y las comunidades indígenas presentes no permite que las categorías "urbano" e "indígena" vayan aparejadas en la literatura jurídica, antropológica y filosófica dominante. La estaticidad de la identidad indígena, como se dijo anteriormente, produce réditos notables para el derecho y la filosofía política. El sujeto de derechos indígenas prehispánico, colonial y moderno es el mismo; no tiene diferencias relevantes. En consecuencia, está justificado que éste sea (o hubiera sido) titular de un conjunto de derechos diferenciados. Ahora bien, el precio que se paga por la unidad y la homogeneidad del indígena es muy alto: el desvanecimiento del indígena urbano; la desaparición de buena parte de lo que constituye lo indígena en el mundo contemporáneo.

En segunda instancia, la invisibilidad de los indígenas urbanos desincentiva la realización de investigaciones que permitan comprender y evaluar las características y dinámicas sociales, culturales, económicas y políticas de estos sujetos y sus comunidades. Si los indígenas urbanos no existen, si estas dos categorías se repelen, no tiene sentido que los antropólogos, juristas académicos o filósofos se pregunten por ellas y las evalúen, conecten y desarrollen ${ }^{71}$. Los indígenas urbanos no son un objeto de estudio legítimo. No vale la pena, por tanto, que se inviertan recursos escasos, como tiempo, energía y dinero, en reflexionar sobre estos temas que, según parece, solo existen en la imaginación febril de algunos pocos individuos. Este hecho genera un círculo vicioso difícil de romper: el marco teórico dominante para pensar lo indígena crea una realidad virtual que impide que se investigue sobre la realidad en el terreno. Los "indicios" e "intuiciones" que indican que existe algo que podría llamarse una comunidad indígena urbana no son, por ende, explorados, confirmados y ampliados. Los componentes aparentemente descriptivos del marco teórico dominante son en realidad dispositivos conceptuales normativos que construyen y transforman la manera como interpretamos la realidad -desconociendo la existencia de los indígenas urbanos. Ahora bien, estas categorías conceptuales normativas dominan nuestra imaginación jurídica y política, no sólo por la fortaleza de sus argumentos y justificaciones, sino porque las herramientas descriptivas de las que se nutren oscurecen secciones importantes de la realidad indígena pasada y contemporánea.

En tercera y última instancia, la invisibilidad de los indígenas urbanos no permite precisar cuáles son sus características y dinámicas culturales típicas, sus intereses, la relación que quieren tener con la sociedad mayoritaria y, por tanto, si deberían ser titulares de derechos diferenciados. Sin embargo, la información disponible en los medios masivos de comunicación y en la poca literatura especializada existente permite pensar que la gran mayoría de los indígenas urbanos (pero de ninguna manera todos ellos) pueden ser designados apelando a las 
siguientes tres categorías. La utilidad de esta tipología no está en que describa de manera precisa todas las comunidades indígenas urbanas que existen actualmente, sino en que articula tres modelos que recogen las características principales de la mayoría de estas colectividades.

La primera categoría de esta tipología es la que quisiera llamar "indígenas tradicionales urbanos". En este caso estamos frente a comunidades indígenas que habitan sus territorios ancestrales. Sin embargo, las tierras en las que viven estas colectividades no son ya rurales; sus predios fueron absorbidos por las estructuras urbanas de la cultura dominante. Los miembros de estas comunidades indígenas son parte de la economía de mercado, la mayoría no conoce o tiene conocimientos débiles de la lengua tradicional y sus conexiones con la cultura tradicional son, en general, tenues. No obstante, la comunidad está interesada en mantenerse como una colectividad particular que se distingue de la cultura mayoritaria. Para lograr este objetivo, muchas de estas comunidades proponen proyectos de reetnización que tienen como fin precisar y difundir las dinámicas culturales de sus antepasados.

Un caso paradigmático de este tipo de comunidades indígenas urbanas sería el de los Muiscas de $\mathrm{Suba}^{72}$ (una de las localidades en las que se divide Bogotá). Este conjunto de individuos desciende de la comunidad indígena Muisca, que pertenece a la familia lingüística chibcha, y que ha habitado la sabana Cundiboyacence desde tiempos prehispánicos. Los Muisca de Suba son propietarios colectivos de su tierra y su organización política, el cabildo, está oficialmente reconocida por la alcaldía de Bogotá. Sin embargo, la mayoría de sus miembros no habla el idioma tradicional y no conocen las tradiciones de sus mayores. De igual forma, estas personas están vinculadas a la economía de mercado de la ciudad y su relación con la tierra incluye dinámicas de explotación agropecuaria que son típicas de una sociedad capitalista. A pesar de esto, la comunidad tiene un interés serio por reconectarse con su cultura tradicional, reproducirla en las mentes y corazones de las nuevas generaciones y, por consiguiente, mantenerse como una cultura distinta de la mayoritaria.

El eje liberalismo multicultural-modelo antropológico indigenista-derecho, no tiene la posibilidad ni de describir de manera precisa a los indígenas tradicionales urbanos, ni de indicar y fundamentar los derechos diferenciados de los cuales podrían ser titulares. El hecho de que habiten zonas urbanas, formen parte de la economía capitalista y hayan perdido buena parte de sus tradiciones culturales no permite que estas comunidades sean calificadas legítimamente como minorías nacionales. Sin embargo, el hecho de que habiten un territorio ancestral, tengan algún conocimiento de las tradiciones e idioma de sus antepasados, un pasado común y el deseo de consolidarse como una comunidad cultural distinta de la mayoritaria podría hacerlas acreedoras de algunos derechos diferenciados ${ }^{73}$.

La segunda categoría de esta tipología de indígenas urbanos sería la que quisiera llamar "indígenas metropolitanos". Esta categoría está compuesta por aquellas 
colectividades que se autodescriben como indígenas pero que habitan en ciudades que no están situadas en sus territorios ancestrales. Estas comunidades, además, emigraron de sus territorios tradicionales huyendo de la violencia, buscando nuevas oportunidades económicas o como consecuencia de políticas de asimilación cultural promovidas por el Estado. De igual forma, la mayoría de sus miembros nació en la ciudad y se ha integrado a la economía de mercado. Finalmente, la generalidad de quienes conforman este tipo de comunidad indígena urbana no habla la lengua tradicional ni conoce profundamente las tradiciones culturales de sus antepasados. Sin embargo, los miembros de estas colectividades tienen un pasado común parcialmente distinto del que tienen aquellos que pertenecen a la cultura mayoritaria, reconocen y valoran sus conexiones con las tradiciones de sus antepasados y quieren mantener un espacio más o menos amplio para manifestar y reproducir su diversidad.

Los indígenas metropolitanos se dividirían a su vez en dos grupos: por un lado, aquellos que podrían legítimamente ser nombrados como un grupo étnico y, por tanto, componen una colectividad que está fundamentalmente integrada en la sociedad mayoritaria pero que quiere mantener espacios para expresar su diferencia; por el otro, aquellos que quisieran conservar, reconstruir o reproducir en la ciudad dimensiones amplias de las tradiciones culturales de sus antepasados, aunque reconocen que son culturalmente diferentes de sus "hermanos" rurales.

Un ejemplo paradigmático del primer tipo de indígena metropolitano sería el de la mayor parte de los indígenas que habitan en Denver. Según una investigación realizada por el Denver Indian Family Resource Center en 2007, más del 40\% de los indígenas que habitan el área metropolitana de esta ciudad consideran que son descendientes directos de hechos de violencia estatal o política o de asimilación forzada, como la masacre de Wounded Knee, Long Walk o el Trail of Tears ${ }^{74}$. Denver no ocupa sus tierras ancestrales. De igual forma, un número notable de estos indígenas ha vivido por periodos considerables en la ciudad. El 62,1\% de estos individuos ha residido en Denver entre 11 y 15 años; el 9,5\%, entre 6 y 10 años y el 7,8\%, entre 3 y 5 años. Sólo el 15,4\% de estos indígenas ha habitado en la ciudad menos de 3 años ${ }^{75}$.

Del mismo modo, el 67,3\% de los indígenas están afiliados formalmente a una comunidad indígena y solo el 11,5\% habla fluidamente el lenguaje tradicional de la comunidad a la que pertenece ${ }^{76}$. Sin embargo, un porcentaje muy alto de los encuestados afirma sentirse orgulloso de ser indígena (promedio de 4,68 en una escala de 5), participar en prácticas culturales (promedio de 3,92 en una escala de 5) y sentirse conectados con otros indígenas en la comunidad (promedio de 3,79 en una escala de 5) ${ }^{77}$. Ahora bien, en Denver, como en muchas otras ciudades de los Estados Unidos, los indígenas se reúnen en organizaciones intertribales que buscan la satisfacción de las necesidades de sus miembros, por ejemplo, instituciones que tratan temas relacionados con la salud, educación y recreación de sus 
asociados. ${ }^{78}$ Algunas de estas organizaciones también promueven y expresan en la esfera pública el legado cultural de las comunidades indígenas a las que están afiliados sus integrantes. ${ }^{79}$

Finalmente, las comunidades indígenas como la de Denver serían multigeneracionales, multitribales, con un pasado común construido en la ciudad y conectadas de manera diversa, pero generalmente tenue, con las tierras de sus ancestros. ${ }^{80}$ En estas comunidades, además, no hay una organización política única que controle y ordene los miembros de la colectividad. Las instituciones que les son útiles se crean a partir de las relaciones sociales panindígenas que se generan en la ciudad, y la pertenencia a la comunidad se determina mediante criterios situacionales y cambiantes, como, por ejemplo, el compromiso con las organizaciones sociales, los rasgos físicos o el porcentaje de sangre indígena que se tenga.

El segundo tipo de indígenas metropolitanos se puede ilustrar de manera paradigmática con los Mapuche que habitan en las ciudades chilenas. Esta es una colectividad urbana que se reconoce como parte de la comunidad indígena Mapuche que habita en varias provincias chilenas pero que acepta que es distinta a la comunidad Mapuche rural. No obstante, también considera que en las áreas metropolitanas reproduce o está en capacidad de recrear parte importante de la cultura tradicional de sus antepasados. Al respecto señala esta colectividad:

Por algunas décadas el Mapuche en la ciudad debió enfrentar la dificultad generada por la teoría que sostenía que el “newen”, la fuerza Mapuche, no se movía del lugar de su origen, o sea la comunidad rural; mucho menos podía generarse en la ciudad, por ello no se podían realizar "nguillatún" en la ciudad porque no había "newen", fuerza, por tanto los Machi se enfermaban. De lo anterior se postulaba que por el hecho de que el Mapuche en la ciudad no desarrollaba su componente espiritual, se llegó a plantear que de alguna manera dejaba de ser Mapuche...[Sin embargo,]el proceso de desarrollo organizacional y creación de identidad en la ciudad demostró que las fuerzas de Futa Chaw-Kuze Nuke están distribuidas en todas partes y se pueden desarrollar. Esta nueva realidad requiere la determinación de espacios territoriales especiales para el desarrollo de la actividad espiritual, para la realización de "nguillatun" dotado de su rewe y su bandera correspondiente... Hemos desarrollado nuestro propio "newen" su propia fuerza espiritual, naturalmente en relación y retroalimentación con la Lof, las comunidades rurales, al igual que los Lonko antiguos, los Ulmen que viajaban de la zona de Temuco al otro lado de la cordillera, al puel mapu y después regresaban a su admapu; hoy, los Mapuche urbanos viajan a sus tierras ancestrales." 81 
El primer tipo de indígenas metropolitanos, según el liberalismo multicultural, parece que solo debe ser titular de derechos culturales que le permitan expresar y defender su diversidad en el contexto de la sociedad mayoritaria a la que pertenece y se ha integrado. Las diferencias entre esta comunidad indígena y un grupo de inmigrantes voluntarios parecerían sólo de grado y no de categoría. El segundo tipo de indígenas metropolitanos, según el liberalismo multicultural, parece poder reclamar legítimamente derechos restringidos de autogobierno que le permitan decidir algunos asuntos relacionados con la vida privada y pública de sus miembros, así como alguna forma reducida de derechos de representación política grupal ${ }^{82}$.

La tercera y última categoría en la tipología de los indígenas urbanos que propongo en este texto es la que quisiera llamar "indígenas urbanos en tránsito". Esta categoría designaría a los indígenas que se asientan por periodos cortos en las ciudades. Estos individuos, como los que estudian en los colegios y universidades, los comerciantes de artesanías o los miembros de organizaciones indígenas que representan los intereses y derechos de comunidades adecuadamente descritas por el modelo antropológico indigenista, son conscientes del carácter temporal de su vida urbana. El fin de su estadía en la ciudad está directamente relacionado con la satisfacción de un objetivo particular. Luego de la materialización de este objetivo está claro que volverán a sus territorios ancestrales. Mientras permanezcan en la ciudad, podría argumentarse desde una posición liberal multicultural, los miembros de estas comunidades tendrían suspendidos sus derechos de autogobierno, pero no sus derechos de representación política grupal. En la ciudad, podrían votar por los candidatos de sus comunidades y podrían ser elegidos para representarlas ante las instituciones del gobierno nacional, estatal o federal. De igual forma, podrían ser titulares de derechos culturales que permitan la defensa y expresión de sus tradiciones culturales.

Esta tipología, sin duda, tiene limitaciones para nombrar la variedad y riqueza de las comunidades indígenas urbanas contemporáneas, así como para precisar los derechos de los que deberían ser titulares. Las colectividades mismas o estudios etnográficos realizados por científicos sociales, por ejemplo, pueden evidenciar que las comunidades que pretenden ser designadas con la tipología que aquí se ofrece poseen características o aspiraciones no descritas por ésta, o no tienen algunas de las que efectivamente se han postulado. Estas precisiones etnográficas, sin duda, podrían generar consecuencias normativas. Podrían, por ejemplo, evidenciar que es necesario articular nuevos tipos de derecho diferenciados; que uno u otro tipo de indígenas urbanos debería poder exigir un conjunto distinto de derechos; o que algunas de estas comunidades no deben ser titulares de derechos diferenciados. Sin embargo, la tipología presentada en este texto parece útil para dar algunos pasos que permitan visibilizar estas colectividades y consolidar y desarrollar las objeciones que muestran los límites del marco teórico dominante para pensar la cuestión indígena -el marco constituido por el liberalismo multicultural, el modelo antropológico 
indigenista y el derecho de un número importante de las democracias liberales que reconocen la diversidad cultural como un bien que vale la pena defender.

: ARTIGO APROVADO (08/12/2011) : RECEBIDO EM 02/09/2011

\section{NOTAS}

1 Profesor Asociado de la Universidad de los Andes, Bogotá, Colombia. Actualmente es Distinguished Leitner Center Visiting Professor, Fordham Law School. Agradezco a Mariana Castrellón por su muy valioso trabajo como asistente de investigación. De igual forma, agradezco a Paul Kahn, Laurel Flethcher, Libardo Ariza, Juan Diego Alvarez y Natalia Ramirez por los muy útiles comentarios que le hicieron a este texto. Versiones preliminares de este artículo fueron presentadas en las facultades de derecho de la Universidad de Palermo y la Universidad de Yale. Agradezco a los asistentes sus comentarios y sugerencias.

2 Joy Harjo, The Path to the Milky Way Leads through Los Angeles, American Indian Culture and Research Journal 22 No4 441 '98. Harjo es una reconocida poeta y música. Forma parte de la comunidad indígena Muscogee, en Estados Unidos. Harjo, a pesar de ser oficialmente miembro de la comunidad Muscogee, nunca ha vivido en la reserva en la que habita la colectividad.

3 Canción de Charlie Hill, comediante Oneida-Mohawk-Cree, citado en Darby Li Po Price, Laughing Without Reservation: Indian Standup Comedians, American Indian Culture and Research Journal $22 \mathrm{~N}^{\circ} 4$ 255-71 '98, pág. 3.

4 Will Kymlicka, 1995, Ciudadanía multicultural, Paidós, Barcelona, 1996, págs. 46 - 55.

5 Ibid, págs. $25-46$.

6 C.fr. Diana Bocarejo, Derechos minoritarios en contextos urbanos: los alcances del multiculturalismo fuera de los territorios étnicos reconocidos, manuscrito.

7 C.fr. Ibid.

8 Actualmente, muchos profesores de antropología reconocen los límites que tiene este modelo para describir la realidad de muchas de las comunidades indígenas contemporáneas Aun así, el modelo conforma el imaginario social a través del cual un buen número de personas se aproximan a los temas indígenas, por ejemplo, funcionarios públicos nacionales, miembros de organismos internacionales y organizaciones no gubernamentales, abogados y miembros de comunidades indígenas. Ahora bien, es preciso anotar que el modelo se nutre de la literatura antropológica del siglo XIX y principios del siglo XX en donde estas descripciones de las comunidades indígenas son comunes y que, en ocasiones, describe la realidad de algunas comunidades indígenas actuales. También es importante anotar que el modelo aparece en algunos textos publicados por antropólogos, particularmente, en aquellos donde se combina trabajo etnográfico con diversas formas de activismo político. Ver, Maximilian C. Forte, Introduction: Indigeneities and Cosmopolitanism, en Maximilian C. Forte (ed.) Indigenous Cosmopolitans, Peter Lang, Publishing, New York, 2010, pág. 1. Para un análisis de la relación entre antropología y la descripción de las comunidades indígenas ver, Andrew Gray, Indigenous Peoples and their Territories, en Adolfo Oliveira (ed), Decolonizing Indigenours Rights, Routledge, 2009. 
La manera como se manifiesta y funciona el modelo indigenista es similar a la manera como se manifiesta y existe el formalismo jurídico. Hoy en día no hay ningún teórico del derecho que defienda de manera explícita este concepto de derecho. Sin embargo, la imaginación de muchas comunidades jurídicas en el mundo está estructurada por las categorías que lo componen. De esta manera, en muchas de estas comunidades, ideas como la identificación del derecho con la ley, la neutralidad de los jueces, la interpretación literal de las normas y el carácter completo y unívoco del derecho, son comunes y aceptadas pacíficamente. De igual forma, este concepto de derecho aparece implícito en los tratados que sistematizan las diferentes áreas que componen el derecho. Las categorías que componen el formalismo jurídico determinan la estructura y contenidos de este tipo de productos académicos.

\section{C.fr. Ibid.}

10 Los Pueblos Indígenas en Áreas Urbanas y la Migración: Retos y Oportunidades, Foro Permanente para las Cuestiones Indígenas de las Naciones Unidas, pág. 2, en http://www.un.org/esa/socdev/ unpfii/documents/6_session_factsheet2_es.pdf

11 Ibid.

12 Kathrin Wessendorf (ed.) The Indigenous World 2009, International Work Group for Indigenous Affairs, pág. 232, en http://www.iwgia.org/graphics/fotos/books/THE\%20INDIGENOUS\%20WORLD2009.pdf

13 Indigenous Affairs: Indigenous Peoples in Urban Areas, 3-4/02, International Work Group for Indigenous Affairs, pág. 6.

14 Kathrin Wessendorf (ed.) The Indigenous World 2009, International Work Group for Indigenous Affairspág. 184.

15 Ibid., pág. 218.

16 The National Urban Indian Family Coalition, Urban Indian America: The Status of American Indian and Alaska Native Children and Families Today, A Report to the Annie E. Casey Foundation, pág., 7 en http://www.nuifc.net/programs/files/NUIFC_PUBLICATION_FINAL.pdf

17 Banco Mundial - República de Colombia, Programa de Familias en Acción: Marco de Referencia para el Programa en Comunidades Indígenas, pág. 9, en http://www.accionsocial.gov.co/documentos/ 1362_MPPI-21-02-07.pdf

18 El seminario Study Space se organizó en Bogotá, Denver y Medellín en años pasados. Este texto, reflexiona en torno a uno de los ejes temáticos alrededor del cual gira este evento: la diversidad cultural en las ciudades. En especial, pretende aproximarse a los retos teóricos que genera el fenómeno de los indígenas urbanos - tema que fue central en el análisis jurídico y trabajo de campo desarrollados en estas tres ciudades por los miembros de Study Space. Para muchos de los participantes de los seminarios realizados en Bogotá, Denver y Medellín fue claro que varias de las categorías jurídicas y de filosofía política con las que usualmente se reflexiona en torno a la diversidad cultural y los derechos de las comunidades indígenas se quedaban cortas para describir y evaluar el fenómeno de los indígenas que viven en las ciudades contemporáneas. Este artículo también se ve influenciado por las discusiones que tuve con Diana Bocarejo sobre temas relacionados con la diversidad cultural en Bogotá y la Constitución de 1991. También tiene como una de sus influencias el siguiente manuscrito: Diana Bocarejo, Derechos minoritarios en contextos urbanos: los alcances del multiculturalismo fuera de los territorios étnicos reconocidos. En este texto, Bocarejo propone como uno de sus objetos de estudio la relación entre indígenas urbanos y liberalismo multicultural.

19 The National Urban Indian Family Coalition, Urban Indian America: The Status of American Indian and Alaska Native Children and Families Today, A Report to the Annie E. Casey Foundation, pág. 9.

Denver, en particular, y Colorado en general fueron, principalmente, el territorio ancestral de los Arapahoe, Cheyenne y Ute (Kathleen Sullivan, Uniting Mountain and Plain: Cities, Law and Environmental Change along the Front Range, University of New Mexico Press, New Mexico, 2002, págs. 43 - 44). Sin 
embargo, como consecuencia, primordialmente, de las políticas de relocalización de las comunidades indígenas del gobierno federal que se implementaron entre 1952 y 1974 y la migración interna en busca de nuevas oportunidades económicas, hoy en día los indígenas que habitan Denver pertenecen a casi 300 comunidades diferentes (Larry W. Burt, Roots of the native American Experience: Relocation Policy in the 1950s, American Indian Quarterly, Vol, 10, N. 2, Spring, 1986, págs. 85 - 99 y Philip Kenneth, The Relocation of Indians to Cities, 1952 - 1960, The Western Historical Quarterly, Vol. 16, No. 2, Apr., 1985, pág. 175 - 190; Denver Indian Family Resource Center, Circle of Care: Keeping the Circle Whole, Adult Community Survey Data Results, April 2007, pág. 6, en http://difrc.org/DIFRCCoCadultsurvey-B\%20(2).doc). Aproximadamente, una tercera parte de estos indígenas son Lakota, un tercio son Navajo, y el resto pertenecen a un grupo muy variado de comunidades como los Kiowas, Apache, Ute, Arapahoe, Cherokee y Oglala Sioux (Final Summary and Documentation, Denver Indian Family Resource Center, pag 2 en http://www.difrc.org/reports.htm y Circle of Care: Keeping the Circle Whole, ibid, pág. 6). Ahora bien, el tiempo que estas comunidades llevan asentadas en Denver varía notablemente. Algunas de las familias de indígenas que viven en esta ciudad lo han hecho por varias generaciones, otras han llegado recientemente y otras son residentes de corto o mediano plazo.

De igual forma, Denver es una ciudad de importancia política y cultural para las comunidades indígenas de los Estados Unidos. Al respecto reporta el New York Times, "'Denver se ha convertido nuevamente en el lugar en donde se cruzan los caminos, el lugar para encontrarse y comerciar', dijo, entre presentaciones en el mercado indígena anual, Jack Gladstone, un músico Piesnegros de Montana. En el extenso archipiélago del País Indígena, Denver está surgiendo como su capital informal. Denver tiene la más grande concentración de organizaciones nacionales indígenas, alrededor de 15 asociaciones, incluyendo la más importante oficina de abogados sobre temas indígenas y el más notable fondo de becas. Que Denver esté siendo empujado al centro del escenario se debe a la neutralidad de la ciudad en materia de asuntos tribales y a su posición central en cuestión de transporte. Libre de la influencia política de alguna reserva grande, Denver está a siete horas manejando de las únicas reservas de Colorado, las tierras ancestrales de los Ute en la esquina suroccidental del estado. En el mundo político de los indígenas urbanos, Denver es la ciudad más importante, dijo, desde Washington, Kevin Gover, Secretario del Interior Asistente para Asuntos Indígenas. El señor Gover, un Pawnee de Oklahoma, quien recientemente vivió en Nuevo México, anotó, 'Si necesitamos un lugar en donde no se le dé preferencia a un grupo sobre el otro, Denver es zona neutral (...). Un punto intermedio entre las reservas de las planicies del Norte y los Pueblos y reservas del Suroeste, Denver es el centro geográfico del Estados Unidos Indio, el grupo racial que está creciendo más rápidamente.” en http://www.nytimes.com/ 1999/02/22/us/indian-country-finds-a-capital-in-denver.html?pagewanted=1 (La traducción es mía).

Denver es uno de los lugares donde radican un número importarte de organizaciones indígenas como el International Institute for Indigenous Resource Management, el Denver Indian Center y el Denver Indian Health \& Family Services. El Denver Pow Wow es un evento cultural de gran importancia para los indígenas del Oeste estadounidense, existen algunos museos reconocidos nacionalmente, como el Colorado History Museum y el Denver Art Museum que recogen y promueven el legado cultural de las comunidades indígenas estadounidenses, y Colorado ha sido el único estado que ha elegido un indígena al Senado de los Estados Unidos, Ben Nighthorse Campbell, quien sirvió entre 1993-2005. Ver, respectivamente, http://www.iiirm.org/; http://www.denverindiancenter.org/; http://www.dihfs.org/index.htm; www.coloradohistory.org; www.denveratmuseum.org; http://bioguide.congress.gov/scripts/ biodisplay.pl?index $=\mathrm{C} 000077$

20 Banco Mundial - República de Colombia, Programa de Familias en Acción: Marco de Referencia para el Programa en Comunidades Indígenas, pág. 10, en http://www.accionsocial.gov.co/documentos/ 1362_MPPI-21-02-07.pdf.

Bogotá es también una ciudad de gran importancia para las comunidades indígenas colombianas. En la ciudad habitan indígenas que provienen de comunidades muy diversas como los Guambianos, Kankuamos, Ingas, Pijaos, Uitotos, Embera, Wayuu y Muisca (Hernán Molina, Nuevos escenarios de vida indígena urbana: el caso de Bogotá, Revista En la Ciudad, Abril de 2007, pág. 105, en http://www.observatorioetnico.org/ descarga/4ep09.pdf ). Las comunidades indígenas que se asentaron en la ciudad lo hicieron fundamentalmente por tres razones: primero, las tierras que hoy ocupa Bogotá son su territorio ancestral - el caso de los Muiscas de Suba y Bosa - ; segundo, llegaron a la capital buscando nuevas oportunidades económicas, como los Kichwa, Inga, Kamentzá, Uitoto y Cofán; y tercero, arribaron desde sus territorios ancestrales desplazados por el conflicto armado colombiano, como los Pijao, Kancuamo y Emberá-Katío.

Ahora bien, la existencia de indígenas en Bogotá no constituye sólo un hecho social; también conforma un hecho político. La alcaldía de Bogotá ha reconocido formalmente la existencia de cinco cabildos, esto es, cinco estructuras de gobierno indígenas en la ciudad: el cabildo Muisca de Bosa, el Muisca de Suba, el Inga, el 
Ambika - Pijao y el Kichwa (Ver Ati Quigua, Concejal de Bogotá, Proyecto de Acuerdo por el cual se establecen los lineamientos de la política para los grupos étnicos, indígenas - raizal - rom y afros, asentados y nativos de Bogotá D.C. y se dictan otras disposiciones, pág. 2; Ver también la página oficial del alcalde de Bogotá Samuel Moreno Rojas, en particular, http://www.samuelalcalde.com/index.php?option= com_content\&view $=$ article $\& i d=4476 \% 3$ Alos-indigenas-tambien-estan-integrados-a-la-ciudad-dederechos\&Itemid=82). Dos asuntos relacionados con este tema llaman particularmente la atención. El primero, que el cabildo Kickwa está conformado por indígenas ecuatorianos que provienen de la provincia de Imbabura, que se asentaron en la ciudad desde los años 30 (Nuevos escenarios de vida indígena urbana: el caso de Bogotá, Ibid, pág. 107). El segundo, que la comunidad indígena Muisca, que habita el cerro de Suba, logró que el gobierno nacional reconociera la propiedad colectiva de su territorio ancestral y conformara formalmente un resguardo dentro de Bogotá.

El Distrito Capital también es relevante para las comunidades indígenas colombianas en tanto que es la sede de organizaciones de importancia nacional como la Organización Nacional Indígena de Colombia, el Consejo Regional Indígena del Cauca, las Autoridades Indígenas de Colombia y la Organización de los Pueblos Indígenas del Amazonas colombiano. (Ver respectivamente, www.onic.org.co; www.cric-colombia.org; www.aicocolombia.org; www.opiac.org.co). De igual forma, en Bogotá están domiciliados el 60\% de los estudiantes universitarios indígenas y es el lugar donde se organizan dos festivales culturales significativos que celebran el legado cultural indígena: el Intirraymi y el de la Chicha (Pedro Cortes, Indígenas universitarios en Bogotá, Revista En la Ciudad, Abril de 2007, pág. 116, http://www.observatorioetnico.org/ descarga/4ep09.pdf).

Finalmente, desde el punto de vista de los indígenas en Colombia, en particular de los indígenas urbanos, Bogotá es de relevancia por dos razones: por un lado, sus ciudadanos eligieron a una de las pocas concejales indígenas que existen en el país, Ati Quigua, quien pertenece a la comunidad indígena Arhuaco y llegó a ser vicepresidente de esta corporación de elección popular; por el otro lado, la Alianza Social Indígena, organización política de carácter nacional, otorgó el aval que permitió que Antanas Mockus se postulara y obtuviera la alcaldía de Bogotá - el segundo cargo político en el país luego de la presidencia de la república (Marta Zambrano, Trazos y borrones en los cambiantes lances de la historia y la memoria social de los indígenas de Bogotá, Ponencia presentada en el Seminario Internacional sobre Memoria e Historia, Ciudad de Guatemala, 2005, págs. 3 y 4, en http://168.96.200.184:8080/avancso/avancso/pon6).

21 Will Kymlicka, La Ciudadanía Multicultural, Paidós, Barcelona, 1996. Ver también, Will Kymlicka, Liberalism and Communitarianism, Canadian Journal of Philosophy 18 (1988): 181-204; y Will Kymlicka, Liberalism, Community and Culture, Oxford, Clarendon, 1989.

22 La versión paradigmática del liberalismo multicultural es la defendida por Will Kymlicka. La Ciudadanía multicultural, ibid, capítulos 5 y 6 . La influencia de su trabajo en la discusión sobre la manera como las minorías culturales deben ser reconocidas y acomodadas por los Estados contemporáneos ha sido enorme. Ver por ejemplo, Sarah Song, Multiculturalism, The Stanford Encyclopedia of Philosophy (Winter 2010 Edition), Edward N. Zalta (ed.), en http://plato.stanford.edu/archives/win2010/entries/multiculturalism/> . Al respecto señala Song, "Will Kymlicka ha desarrollado la más influyente teoría sobre el multiculturalismo basada en los valores liberales de autonomía e igualdad”. Ver también, Duncan Ivison, Paul Patton y Will Sander, Introduction, en Political Theory and the Rights of Indigenous Peoples, Duncan Ivison, Paul Patton y Will Sander(eds.), Cambridge University Press, 2000, págs. 7 y 8.

23 Véanse, J. Raz y A. Margalit (1990), National Self-Determination, Journal of Philosophy 87: 12-34; Charles Taylor, Multiculturalismo y política del reconocimiento, Fondo de Cultura Económica, 1993 y Will Kymlicka,, Liberalism, Community and Culture, Oxford, Clarendon, 1989.

24 Kwame Anthony Appiah, The Ethics of Identity, Princeton University Press, Princeton, 2005 pags, $120-130$

25 Ibid.

26 "La cultura, se dice, no es un mero instrumento de los bienes individuales. No se puede distinguir de ellos como una condición meramente contingente, algo sin lo cual en principio podrían existir. Esto no tiene sentido. [La cultura] Está esencialmente conectada con lo que hemos identificado como bueno, no solo en un sentido instrumental débil... sino como algo intrínsecamente bueno. Decir que un cierto tipo de heroísmo 
como la autoentrega es bueno, o que cierta cualidad de la experiencia estética lo es, implica juzgar como buenas las culturas en el que este tipo de heroísmo y este tipo de experiencia son opciones concebibles. Si vale la pena cultivar tal virtud y esta experiencia, tiene que valer la pena proteger las culturas que las hacen posibles, no como instrumentos contingentes, sino por sí mismas." Charles Taylor, Irreducibly Social Goods, en Philosophical Arguments, Charles Taylor, Harvard University Press, Cambridge, 1995, pág. 137. (La traducción es mía).

27 Jeremy Waldron, Theoretical Foundations of Liberalism, The Philosophical Quarterly, Vol 37, N. 147 (Apr., 1987), pág. 147

28 Ahora bien, algunos liberales aceptan que el liberalismo político está íntimamente relacionado con el liberalismo ético. La ética liberal fundamenta la política liberal. Este hecho implica que entre la esfera privada y la pública hay estrechos vasos comunicantes. Sin embargo, esta continuidad entre la moral liberal y la justicia liberal no implica que las diferencias entre la órbita de lo público y la órbita de lo privado desaparezcan. El Estado, de todos modos, tiene prohibido cruzar la frontera que existe entre estos dos espacios conceptuales y materiales - aunque estos dos espacios estén constituidos por valores liberales. De lo contrario el individuo no tendría espacio alguno para construir autónomamente su identidad. Ronald Dworkin, Etica privada e igualitarismo político, Paidós, Barcelona, 1993, págs., 49 - 66.

29 Ronald Dworkin, Liberalism, en Ethische und politische Freiheit, Julian Nida-Rümelin, Wilhelm Vossenkuhl (eds.), Walter de Gruyter, New York - Berlín, 1998, págs. 180 -204.

30 Multiculturalismo y política del reconocimiento, Ibid., págs. 67 - 68 y 85 - 91; Will Kymlicka, Ciudadanía multicultural, Paidós, Barcelona, 1996, pág. 80.

31 Ibid., págs. 47 - 52 y J. Raz y A. Margalit (1990), National Self-Determination, Journal of Philosophy 87: 12-34

32 El antropólogo Deward Walker afirma, "A lo largo de la región del Norte de las montañas Rocosas, los líderes religiosos de los indígenas estadounidenses atestiguan que la ubicación geográfica de los rituales es vital. Si los rituales no se practican en los lugares apropiados, éstos tienen poca o ninguna eficacia. En un sentido literal, el ambiente natural se convierte en el altar o iglesia de estas religiones. Se ha documentado que otros indígenas a lo largo del Noroeste, Suroeste, tierras pantanosas del Este, Sub-ártico y regiones del ártico norteamericano tienen concepciones similares. La regla antes que la excepción es que la vida ritual de los indígenas estadounidenses esté ligada inextricablemente con el ambiente natural" Deward Walker Jr. Protection of American Indian Sacred Geography en Christopher Vecsey, (ed), Handbook of American Indian Religious Freedom, New York, New York, The Crossroad Publishing Company, 1991, pág. 110. A este respecto también señala Walker, "la geografía sagrada es una característica universal y esencial de la práctica de las religiones de los indígenas estadounidenses.” Ibid., pág. 101. Richard Stoffle y Michael Evans señalan en relación con este tema, "Estudios etnográficos previos, incluyendo aquellos que hacen parte de este análisis, indican que los indígenas estadounidenses frecuentemente perciben los recursos culturales como elementos de un todo único. Esta premisa epistemológica se expresa usualmente a través del concepto de la integración de los humanos, la naturaleza y lo sobrenatural (...). Una implicación de esta premisa es que los indígenas se perciben a sí mismos como parte funcional y esencial de los elementos naturales que existen en las tierras que han ocupado tradicionalmente. Ellos perciben que esta relación ha sido causada por lo sobrenatural (...). Las tierras ancestrales, por tanto, son sus tierras sagradas". Richard W Stoffle y Michael J. Evans, Holistic Conservation and Cultural Triage: American Indian Perspectives on Cultural Resources, Human Organization, 1990, 49(2) 91-92 (la traducción de las anteriores citas es mía). Para ver los nexos entre un número amplio de las religiones que profesan las comunidades indígenas en los Estados Unidos y sus territorios, véase, Robert Charles Ward, The SpiritsWill Leave: Preventing the Desecration and Destruction of Native American Sacred Sites on Federal Land, 19 Ecology L.Q. 795, 800-02 (1992). Véase también, Susan Lobo, Is Urban a person or a Place? Characteristics of Urban Indian Country, American Indian Culture and Research Journal, UCLA American Indian Studies Center, Volume 22, Number 4/1998 y Libardo Ariza, Derecho, saber e identidad indígena, Siglo del Hombre Editores, Universidad de los Andes, Pontificia Universidad Javeriana Instituto Pensar, 2009. Al respecto señala Ariza, "Por ahora, solo se resalta esta relación esencial, constitutiva e indisoluble entre un territorio y la existencia de una identidad y su respaldo por parte del saber antropológico", Ibid, pág. 252. 
33 Will Kymlicka, American Multiculturalism and the Nations Within, en Duncan Ivison, Paul Patton and Will Sander (eds), Political Theory and the Rights of Indigenous Peoples, Cambridge, UK, Cambridge, 2000, págs. 221 - 227; William E. Connoly, The Liberal Image of the Nation, en Ibid; and Audra Simpson, Paths Toward a Mohawk Nation: Narratives of Citizenship and Nationhood in Kahnawake, en Ibid.

34 En relación con este punto señalan varios líderes indígenas colombianos, "Este derecho a la autonomía, que tenemos los pueblos indígenas sobre nuestros territorios y recursos, se debe valorar y respetar, antes de realizar o gestionar cualquier tipo de acción o política que lo afecte. Solamente el conocimiento que respalda esta autonomía proporciona herramientas y elementos necesarios para hacer propuestas que se traduzcan en nuestra conservación como pueblos y en posibilidades de dar un manejo equilibrado a nuestros territorios, garantía no sólo de nuestra supervivencia sino del futuro de la nación." Organización Regional Embera Wounaan (OREWA), Autonomía Territorial y Jurisdicción Indígena en Del Olvido Surgimos para Traer Nuevas Esperanzas, Ministerio De Justicia y del Derecho, Bogotá, 1997. Compilación de ponencias del Primer Seminario Nacional sobre Jurisdicción Indígena y Autonomía territorial, pág. 141. De igual forma, el Gobernador del Cabildo Mayor del Pueblo Kogi y un miembro del pueblo Arhuaco señalan que, "Los indígenas en Colombia tenemos distintas formas de organización y dialectos, distintas normas de la justicia interna y distinta la forma de vestir. A muy pocas comunidades nos ha quedado la autonomía, de pronto unas comunidades lo deben tener más todavía, las costumbres, otras menos y otras más. En estos momentos es necesario buscarles unidad y acuerdo y volver a llegar donde vivían nuestros abuelos o llegar en el mismo territorio, llegar el pensamiento indígena con un dialecto propio, con estilo propio, la educación propia y el esfuerzo que se ha venido es una lucha no de antier sino que hace ratos que nuestros dirigentes y nosotros luchamos para defender nuestra culturas y la autonomía." Arregocés Conchalá Zalabata y Danilo Villafañe Torres, Autonomía y Cultura en los Kággaba, Iky y Wiwa de la Sierra Nevada de Santa Marta en Ibid, pag. 104; De la misma manera, un miembro del Pueblo Indígena Emberá-Catío y de la Organización Indígena Emberá Wounaan (OREWA), señala, “El trabajo sobre la autonomía territorial no es lesivo a ninguna sociedad ni mucho menos al mismo Estado, como tratan de macartizar esta aspiración. Todo el ejercicio de la autonomía territorial para nosotros, los pueblos indígenas del Pacífico y en especial para los Emberá, debe partir de lo cultural, debe partir de las percepciones de cada uno, de esa cosmovisión desde su origen, desde las normas que dejó el creador de los pueblos indígenas que tenga cada pueblo, o sea de lo que se ha hablado en los 82-83 pueblos indígenas existentes en Colombia.”. Alberto Achito, Autonomía Territorial, Jurisdicción Especial Indígena y Conflictos Interétnicos en el Pacífico en Ibid., pág. 53. Ver también, Arregocés Conchalá Zalabata y Danilo Villafañe Torres, Autonomía y Cultura en los Kággaba, Iky y Wiwa de la Sierra Nevada de Santa Marta en Ibid., pág. 90; Alvaro Morales Tunubalá, El Pueblo Guambiano y su Justicia Tradicional ante la Jurisdicción Especial Indigena en Ibid, pág. 85; Leonor Zalabata, Principios de Autonomía entre el Pueblo Arhuaco, Vertiente Valledupar en Ibid, págs. $67-69$.

35 Jefe Seattle, Citado en Don Coyhis, Fall: Meditations with Native American Elders, 1994, pág. 82. A este respecto señalan los líderes indígenas Robinson y Piñacue, respectivamente. "En opinión de mi gente, cada parte de esta tierra es sagrada. Cada ladera, cada valle, cada pradera y arboleda, fueron bendecidos por un evento triste o feliz en días que desaparecieron hace mucho tiempo". (La traducción es mía). Chief Roderick Robinson, Nisga'a, citado en Ibid. pág. 55; y "La autonomía la entendemos como la posibilidad real de preservar nuestra identidad étnica y cultural dentro de un ámbito territorial en el cual se conserva la memoria colectiva, por existir los lazos tendidos entre el Nasa y la naturaleza.” Jesús Enrique Piñacue, Aplicación Autonómica de la Justicia en Comunidades Paeces: Una Aproximación en Del Olvido Surgimos para Traer Nuevas Esperanzas, Ministerio De Justicia y del Derecho, Bogotá, 1997, Compilación de ponencias del Primer Seminario Nacional sobre Jurisdicción Indígena y Autonomía territorial, pág. 48.

36 Asamblea Nacional Constituyente, Ponencia, Los Derechos de los Grupos Étnicos. Constituyente Francisco Rojas Birry, Gaceta Constitucional Nº. 67, pág. 18.

37 Susan Lobo, Is Urban a Person or a Place? Characteristics of Urban Indian Country, American Indian Culture and Research Journal 22, N.4,89-102, 1998, págs. 4 - 6

38 Esta asociación se puede ver claramente en varios de los escritos que aparecen en las memorias del IV Congreso latinoamericano de la Red de Antropología Jurídica. Así, por ejemplo, Iza Rona dos Santos afirma, "Hablo en nombre de mis parientes Macuxi, Wapichana, Ingarikó, Taurepang y Patamona, lo hago para que sean escuchados sus esfuerzos por defender aquello que definimos como la razón primordial de nuestra 
existencia: el TERRITORIO, sin el cual la vida en su plenitud no existe (...). En silencio nuestra estrategia principal es no abandonar nuestros territorios ancestrales, hacer eso es abandonar nuestra vida (...). El mundo cosmológico de estos pueblos, la relación con la tierra y la naturaleza proporciona plena conservación del ambiente, un área de rica diversidad biológica e importantes manantiales del agua." Iza Roná dos Santos, Raposa Sierra del Sol: 30 años de lucha por el respeto a un derecho irrevocable, en Pueblos en Lucha, Raposa Sierra del Sol Camisea - Awas Tingni - Sarayaku, Memoria del Foro: Casos emblemáticos de defensa de derechos indígenas IV Congreso latinoamericano de la Red de Antropología Jurídica, Agosto, 2004, Quito Facultad latinoamericana de ciencias sociales, págs. 10 y 17; al respecto indica Mario Melo, “¿Es lícito que un Estado, por razones meramente económicas e incluso por la fuerza, en contra de la voluntad explícita del pueblo indígena directamente afectado, promueva la realización de actividades extractivas de recursos naturales dentro del territorio sagrado de dicho pueblo; las que, sin lugar a dudas, provocarán no solo la degradación del entorno natural, sino también serios impactos en el modo de vida de la comunidad, su cultura, sus valores y su espiritualidad, hasta el punto de poner en riesgo sus posibilidades de desarrollo como pueblo? Mario Melo, El caso Sarayaku y los derechos humanos: ¿Por qué Sarayaku constituye un caso emblemático de exigibilidad de derechos a nivel internacional?, en Ibid, págs. 50 - 51; finalmente, José Serrano indica, "Cuando nos referimos a los derechos de los pueblos indígenas, hablamos de la integralidad de sus derechos; cuando mencionamos su derecho a su territorio, vamos más allá de mencionar lo que representa la tierra y su superficie, nos referimos a su hábitat, a su cultura, a su educación, a su salud, a sus animales (...). A manera de conclusión me permito mencionar ciertos elementos que nos pueden ayudar a comprender el vínculo indivisible entre la tierra, el territorio y los pueblos indígenas (...).”; José Serrano, Conclusiones de la mesa sobre las experiencias de lucha de los pueblos indígenas, en Ibid, págs. 23 y 26.

39 “Todo en la naturaleza tiene un espíritu, y toda 'la creación está interrelacionada' en una comunidad holística que incluye a todos los seres animados - humanos, animales, plantas, seres espirituales y geografía. En tanto que la naturaleza es un ciclo en el que esta comunidad más grande opera, ser propietario de la tierra no tiene sentido. La tierra es simplemente un espacio en donde esta 'red de interrelaciones' entre seres animados acontece, y, 'la tierra es uno de los parientes más cercanos [de los indígenas]'. No se es propietario de la tierra, por tanto, en el sentido de retener una parte de ella por un periodo particular de tiempo. En cambio, las canciones, historias y ceremonias de un pueblo son la base para establecer que existe una relación con un pedazo de tierra particular." Robert Retherford, A Local Development Agreement on Access to Sacred Lands, 75 UCOLOR 963, pág. 6, citando a Leroy Little Bear, Aboriginal Relationships to the Land and Resources, en Sacred Lands: Aboriginal World Views, Claims, and Conflicts 17, Jill Oakes, et al. (eds.), 1998, págs. 6,18, 19 y 42; Al respecto señala Rebecca Tsosie, la idea de que la naturaleza es una inmensa red, "combinada con la profundamente enraizada ética de la reciprocidad y el balance, [y que] conduce a una perspectiva de estabilidad ecológica de largo plazo o (...) a una preocupación por la 'sostenibilidad'”. Rebecca Tsosie, Tribal Environmental Policy in an Era of Self-Determination: The Role of Ethics, Economics, and Traditional Ecological Knowledge, $21 \mathrm{Vt}$. L. Rev. 225, 248 (1996), pág. 285. De igual forma señala Tsosie, "La tierra es un ser vivo, consciente, que tiene que ser tratado con respeto y cuidado". Ibid, pág. 276. Curtis afirma sobre este tema, "Los miembros tradicionales de la tribu creen que algunos elementos del ambiente natural tienen su propia esencia espiritual y que el hombre es una parte integral de este sistema." Sue Ann Curtis, Cultural Relativism and Risk-Assessment Strategies for Federal Projects, Human Organization, 1992, 51(1), pag 67; Vine Deloria indica sobre este tema, "Para muchas religiones indígenas toda la creación fue buena," por tanto, "todas las partes [de la creación] funcionan juntas para sostenerla.” Vine Deloria, Jr., God is Red (1992), pág. 81. (Las traducciones son mías).

40 Bradley Reed Howard, Indigenous Peoples and the State, Northern Illinois University Press, 2003, págs. 29-30.

41 Mario Blaser, Indigenous Peoples, Civil Society and the Environment, en Adolfo de Oliveira, Decolonising Indigenous Rights, Routledge, 2009, pág. 193.

42 Para un excelente análisis del nexo entre el discurso multicultural y el discurso ambientalista ver, Libardo Ariza, Derecho, saber e identidad indígena, Siglo del Hombre Editores, Universidad de los Andes, Pontificia Universidad Javeriana - Instituto Pensar, 2009, capítulos 4, 5 y 6.

43 Ibid, págs. 256 y 283.

44 "Como los europeos antiguos, los indígenas tradicionalmente ven a la naturaleza como una 'fuerza formidable $(\ldots)$, siempre sobrecogedora y poderosamente intimidante'. Sin embargo, los indígenas han visto 
su relación con la naturaleza como una de dependencia frente a un creador benéfico, antes que como una de lucha por su dominio. Dada esta relación benéfica, la tarea de las religiones indígenas 'es determinar la relación apropiada que la gente de la tribu tiene que tener con otras cosas vivas', determinar cómo actuar 'armoniosamente con otras creaturas' incluyendo la tierra. Como una parte necesaria de la creación, el paisaje incluye el mundo espiritual”. Robert Retherford, A Local Development Agreement on Access to Sacred Lands, 75 UCOLOR 963, pág. 3, citando a Donald L. Fixico, The Struggle for Our Homes, en Defending Mother Earth 41, Jace Weaver (ed.), 1997, pág. 34 y 88. Véase también, Andrew Gulliford, Sacred Objects and Sacred Places: Preserving Tribal Traditions, University Press of Colorado, 2000, pág. 67.

45 "Las formas tradicionales de producción y la organización especializada que caracteriza a esta comunidad han permitido que los Ika sobrevivan en un medio ecológico con tendencia a hostilizarse por las graves condiciones de deterioro ambiental que agentes externos a la Sierra han generado (...). Al decir de los Mamos, 'Antes de llegar el hermanito menor había bosque hasta la playa, también había mucho indígena en la Sierra y alrededor. Ellos no talaban para que no hubiera enfermedades y para que el agua se alimentara y los árboles se alimentaran por medio del vapor de las nubes. Los indígenas, los árboles y el agua se respetaban por igual; los árboles respetaban el agua y nosotros a los árboles y el agua a nosotros, todos nos respetábamos por igual (...). Pero hermanito menor dijo que si no tenía finca no era señor; si no tenía ganado no era señor, era salvaje, y así toda la gente empezó a tumbar el bosque, comprar ganadito y finca. Por eso hoy en día es muy difícil recuperar todo. Ahora nos ataca la enfermedad, el hambre; se acaba la quebrada, se seca el río (...). Pero el mismo Serankua dijo que el aparato material podría dañar el corazón de todo mundouniverso. Porque la Sierra es corazón. Otras montañas pueden ser codos y rodillas, pero aquí está el corazón (...). Si se enferma el Corazón todo se enferma (...)."Corte Constitucional, Sentencia SU-510-98 - M.P. Eduardo Cifuentes.

46 Manuhai Barcham, (De)Constructing the Politics of Indigeneity, en Duncan Ivison, Paul Patton and Will Sander, Political Theory and the Rights of Indigenous Peoples, Cambridge, UK, Cambridge, 2000.

47 Libardo Ariza, Derecho, saber e identidad indígena, Siglo del Hombre Editores, Universidad de los Andes, Pontificia Universidad Javeriana - Instituto Pensar, 2009, pág. 247.

48 Craig Proulx, Aboriginal Hip Hoppers: Representin'Aboriginality in Cosmopolitan Worlds, en Maximilian C. Forte (ed.) Indigenous Cosmopolitans, Peter Lang, Publishing, New York, 2010, pág. 40.

49 Un ejemplo que ilustra este argumento es el que presenta Schryer respecto de la comunidad Nahua del Alto Balsas. Ver, Frans J. Schryer, The Alto Balsas Nahuas: Transnational Indigeneity and Interactions in the World of Arts and Crafts, the Politics of Resistance, and the Global Labor Market, en Maximilian C. Forte (ed.) Indigenous Cosmopolitans, Peter Lang, Publishing, New York, 2010, págs. 101-102.

50 Al respecto señala James Anaya, "La Corte Interamericana de Derechos Humanos y el Comité de Derechos Humanos de la ONU en los casos previamente mencionados reconocen la importancia que tienen las tierras y los recursos para la supervivencia de las culturas indígenas y, por implicación, para la autodeterminación de los indígenas. Esta interpretación constituye un principio ampliamente aceptado por el movimiento internacional contemporáneo que se preocupa por los pueblos indígenas. Deriva de las ideas articuladas por los pueblos indígenas sobre el manejo comunal de la tierra y el profundamente sentido nexo espiritual y emocional que tienen con la tierra y sus frutos. Aún más, los pueblos indígenas típicamente han buscado una base segura de tierra y recursos naturales para asegurar la viabilidad económica y el desarrollo de sus comunidades.”. (La traducción es mía). James Anaya, Indigenous Peoples in International Law, New York, Oxford University Press, 2004, págs. 104-105

51 Francesco Capotorti, Study on the Rights of Persons Belonging to Ethnic, Religious and Linguistic Minorities, págs. $40-41,98$-99, U.N. Doc. E/CN.4/Sub. 2/384/Rev. 1 (1979). Sobre este tema ver igualmente, Jeremy Waldron, The Cosmopolitan Alternative, 25 U. Mich. J.L. Reform 1991 - 1992, págs. 757 759 (en donde analiza la cultura de las minorías como un derecho humano). Otros documentos de la ONU en la misma línea son los siguientes: United Nations Economic and Social Council, Study of the Problem of Discrimination against Indigenous Populations: Conclusions, Proposals, and Recommendations, Vol. 5, by José R. Martínez Cobo, special rapporteur,E/CN.4/Sub2/1986/7/Add.4, pags, 29, 39-41; y Report of the Human Rights Committee, U.N. GAOR, 45th Sess., Supp. Nº.40, U.N. Doc. A/45/40, vol 1, pág. 95. 
52 El artículo 8 del Convenio en su numeral segundo afirma que "dichos pueblos deberán tener el derecho de conservar sus costumbres e instituciones propias, siempre que éstas no sean incompatibles con los derechos fundamentales definidos por el sistema jurídico nacional ni con los derechos humanos internacionalmente reconocidos. Siempre que sea necesario, deberán establecerse procedimientos para solucionar los conflictos que puedan surgir en la aplicación de este principio”.

53 Artículo 6: 1. "Al aplicar las disposiciones del presente Convenio, los gobiernos deberán: a) consultar a los pueblos interesados, mediante procedimientos apropiados y en particular a través de sus instituciones representativas, cada vez que se prevean medidas legislativas o administrativas susceptibles de afectarles directamente; b) establecer los medios a través de los cuales los pueblos interesados puedan participar libremente, por lo menos en la misma medida que otros sectores de la población, y a todos los niveles en la adopción de decisiones en instituciones electivas y organismos administrativos y de otra índole responsables de políticas y programas que les conciernen; c) establecer los medios para el pleno desarrollo de las instituciones e iniciativas de esos pueblos y, en los casos apropiados, proporcionar los recursos necesarios para este fin."

54 Artículo 9: 1. "En la medida en que ello sea compatible con el sistema jurídico nacional y con los derechos humanos internacionalmente reconocidos, deberán respetarse los métodos a los que los pueblos interesados concurren tradicionalmente para la represión de los delitos cometidos por sus miembros".

55 Artículo 14: 1. "Deberá reconocerse a los pueblos interesados el derecho de propiedad y de posesión sobre las tierras que tradicionalmente ocupan. Además, en los casos apropiados, deberán tomarse medidas para salvaguardar el derecho de los pueblos interesados a utilizar tierras que no estén exclusivamente ocupadas por ellos, pero a las que hayan tenido tradicionalmente acceso para sus actividades tradicionales y de subsistencia. A este respecto, deberá prestarse particular atención a la situación de los pueblos nómadas y de los agricultores itinerantes. 2. Los gobiernos deberán tomar las medidas que sean necesarias para determinar las tierras que los pueblos interesados ocupan tradicionalmente y garantizar la protección efectiva de sus derechos de propiedad y posesión. 3. Deberán instituirse procedimientos adecuados en el marco del sistema jurídico nacional para solucionar las reivindicaciones de tierras formuladas por los pueblos interesados."

56 Artículo 15: 1. "Los derechos de los pueblos interesados en los recursos naturales existentes en sus tierras deberán protegerse especialmente. Estos derechos comprenden el derecho de esos pueblos a participar en la utilización, administración y conservación de dichos recursos. 2. En caso de que pertenezca al Estado la propiedad de los minerales o de los recursos del subsuelo, o tenga derechos sobre otros recursos existentes en las tierras, los gobiernos deberán establecer o mantener procedimientos con miras a consultar a los pueblos interesados, a fin de determinar si los intereses de esos pueblos serían perjudicados, y en qué medida, antes de emprender o autorizar cualquier programa de prospección o explotación de los recursos existentes en sus tierras. Los pueblos interesados deberán participar siempre que sea posible en los beneficios que reporten tales actividades, y percibir una indemnización equitativa por cualquier daño que puedan sufrir como resultado de esas actividades."

57 La mencionada alianza aparece también en algunos análisis de estas sentencias. Al respecto señala Mike Berraondo, "La propiedad de los territorios se ha convertido en una cuestión de máxima urgencia para garantizar la permanencia de las culturas indígenas, el derecho a utilizar y beneficiarse de las tierras siguiendo las costumbres y tradiciones y para frenar el intrusismo y la degradación que sus territorios sufren debido a la acción de colonos y empresas multinacionales. Y la utilización de sus tierras y recursos naturales según las costumbres tradicionales y culturas es fundamental para el mantenimiento de las culturas de estos pueblos y sus formas de vida" Mikel Berraondo, Lecciones del caso Awas Tingni tres años después de la sentencia de la Corte Interamericana en Pueblos en Lucha, Raposa Sierra del Sol - Camisea - Awas Tingni - Sarayaku, Memoria del Foro: Casos emblemáticos de defensa de derechos indígenas IV Congreso Latinoamericano de la Red de Antropología Jurídica, Agosto, 2004, Quito Facultad latinoamericana de ciencias sociales, pág. 3; Mikel Berraondo, El caso Awas Tingni: la esperanza ambiental indígena, en Felipe Gomez (ed), El caso Awas Tingni contra Nicaragua: nuevos horizontes para los derechos humanos de los pueblos indígenas, Universidad de Deusto, 2003, pág. 60; y Mikel Berraondo López, Pluralismo jurídico, medio ambiente y pueblos indígenas. Hacia un nuevo derecho humano al medio ambiente, en http://www.pucp.edu.pe/ridei/pdfs/081228.pdf, pag 6.

58 Sentencia de la Corte Interamericana sobre la Comunidad Mayagna (Sumo) Awas Tingni vs. Nicaragua , 31 de agosto de 2001, párrafo 149. En Saramaka señala la Corte, "las decisiones de la Corte al respecto se 
han basado en la relación especial que los integrantes de los pueblos indígenas y tribales tiene con su territorio, y en la necesidad de proteger su derecho a ese territorio, a fin de garantizar la supervivencia física y cultural de dichos pueblos". Corte Interamericana de Derechos Humanos, Caso del pueblo Saramaka vs. Surinam, Sentencia del 28 de noviembre de 2007, párrafo 90. En Moiwana la Corte indica, "En este sentido, los miembros de la comunidad, un pueblo tribal N. djuka, poseen una relación omnicomprensiva con sus tierras tradicionales, y su concepto de propiedad en relación con ese territorio no se centra en el individuo, sino en la comunidad como un todo". Corte Interamericana de Derechos Humanos Caso de la Comunidad Moiwana vs. Suriname. Sentencia del 15 de junio de 2005, párrafo 133.

59 La influencia de estas dos perspectivas se hizo evidente desde las discusiones que se dieron en la Asamblea Nacional Constituyente que redactó la Constitución de 1991. En particular, en las ponencias presentadas por los constituyentes indígenas Franscico Rojas Birry y Lorenzao Muelas. Al respecto señala Birry, "cada grupo étnico ha escrito sobre el tiempo el mensaje de la vida que merece ser vivida (...). Pero este derecho se volvería nulo si no se tiene la posibilidad de seguir viviendo como se quiere vivir, si hay que vivir de acuerdo con los requerimientos de otros que desconocen el significado de la vida, tal como la vive cada grupo étnico (...). Esto justifica el derecho colectivo a la autonomía: el derecho a tener formas propias de organización social, formas propias de gobierno o de justicia, a tener una educación y unas formas de medicina propia, etc." Francisco Rojas Birry, Los derechos de los grupos étnicos, en Gaceta Constitucional Nº. 67., pág. 18. Frente a este tema afirma Muelas, "por eso la Constitución Nacional, si quiere garantizar la libertad de ser y de hacer, es decir los derechos de cada cual, tiene que tomar en cuenta lo que somos y lo que hacemos cada cual; y no meternos a todos dentro del mismo saco 'otorgándonos' idénticos derechos, o imponiéndonos iguales obligaciones. Porque la verdad es que durante toda la República, lo único que 'democráticamente' se nos ha ofrecido es el 'derecho' a ser como otros, como no queremos ser." Lorenzo Muelas, Proyecto de Acto Reformatorio de la Constitución Política de Colombia, en Gaceta Constitucional No. 24., pág. 14.

60 Los siguientes derechos, que desarrollan o facilitan el autogobierno de las minorías culturales, hacen parte también del grupo de derechos que protegen a las comunidades indígenas: la declaración según la cual los territorios aborígenes están por fuera del comercio (Const.Col. art.63) y el reconocimiento de que las tierras aborígenes tienen el carácter de "entidades territoriales" como los departamentos o los municipios (arts.287, 288, 289). Esta categoría está conformada también por el reconocimiento de la propiedad colectiva de los territorios indígenas (art.329) y por la declaración de acuerdo con la cual la explotación de los recursos naturales dentro de las tierras indígenas debe hacerse sin afectar negativamente la integridad social, económica y cultural de las comunidades (art.330). Esta categoría de derechos incluye asimismo la obligación del Estado de promover la participación de las comunidades indígenas en los procesos de toma de decisiones relacionados con la explotación de los recursos naturales dentro de sus tierras (art.330, parágrafo). Finalmente, incluye la creación de un distrito electoral especial en el Senado para los pueblos indígenas (art.171), la declaración constitucional de que la ley puede crear un distrito electoral especial en la Cámara de Representantes para las minorías culturales (art.176), el derecho de las comunidades que posean sus propias tradiciones lingüísticas a una educación bilingüe (art,.10), el derecho a una educación que respete y desarrolle la identidad cultural de las minorías culturales (art.68), y el reconocimiento de que los idiomas de los grupos indígenas son idiomas oficiales dentro de su territorio (art.10).

61 Ver Daniel Bonilla, La Constitución Multicultural, Siglo del Hombre Editores - Universidad de los Andes - Instituto Pensar, 2006, capítulos 3 y 4.

62 Las decisiones expedidas por la Corte Suprema de Justicia en relación con la responsabilidad penal de los indígenas colombianos (Corte Suprema de Justicia cuando aún estaba vigente la Constitución de 1886) también se ven influenciadas por el modelo antropológico indigenista. Ver, Sala de Casación Penal, Sentencia del 23 de julio de 1948 (Gaceta Judicial 2064-2065) y Corte Suprema de Justicia, Sala de Casación Penal, Sentencia del 22 de septiembre de 1950. En estas sentencias, la Corte Suprema identifica al indígena con un territorio ancestral rural y salvaje. Esta misma asociación aparece también en la ley 89 de 1890, todavía hoy vigente. Esta ley regula (o regulaba, en tanto que algunos de sus apartes han sido derogados o declarados inconstitucionales por la Corte Constitucional) aspectos centrales de la relación entre el Estado colombiano y las comunidades indígenas, por ejemplo, la relación indígenas, Estado y misiones católicas. Históricamente, esta ley ha sido fundamental para proteger los territorios indígenas oficialmente reconocidos. Al respecto señala Piedad Tello, “curiosamente el indígena ha encontrado medios legales a su alcance para exigir sus derechos. La principal arma que ha esgrimido en su defensa y la del resguardo ha sido la Ley 89 de 1890 . El carácter discriminatorio de la 
ley ha sido invertido para exigir su derecho a ser diferente, a desarrollar su cultura dentro de un territorio propio (...). Así, el indio se apropió y cambió el significado del término hasta convertir la lucha por el resguardo en la lucha por su sobrevivencia, pues en su discurrir, los dos términos se funden: no se reconoce indígena sin resguardo ni resguardo sin indígenas como lo demuestra, en su particularidad, la historia de las parcialidades en el Cauca, Huila, Nariño y Tolima". Piedad Tello, Aspectos históricos del resguardo indígena y su defensa a fines del siglo XIX e inicios del XX, Revista de Antropología, Vol II - Nº 1 - 2, 1986, pág. 151. Sobre el nexo histórico e ineludible entre indígenas y territorio ancestral es particularmente ilustrativa la ley 13 de 1903, que extinguió el resguardo de Timbio porque sus habitantes habían dejado de ser verdaderos indígenas. Ibid, pág. 140.

63 Sentencia T-188/93 - M.P. Eduardo Cifuentes. En esta misma sentencia también señala la Corte, "El derecho fundamental a la propiedad colectiva de los grupos étnicos lleva implícito, dada la protección constitucional del principio de diversidad étnica y cultural, un derecho a la constitución de resguardos en cabeza de las comunidades indígenas." Ver también Corte Constitucional, Sentencia T-634 de 1999 - M.P. Alejando Martínez Caballero (sobre economía de subsistencia y "solidarismo" indígena); Corte Constitucional, Sentencia T-342 de 1994 - M.P. Antonio Barrera Carbonell (sobre la estrecha relación entre naturaleza e indígenas); Corte Constitucional, Sentencia SU-039 de 1997 - M.P. Antonio Barrera Carbonell (sobre la estrecha relación entre naturaleza e indígenas); y Corte Constitucional, Sentencia C-058 de 1994 - M.P. Alejandro Martínez Caballero (sobre el servicio militar obligatorio y el argumento que indica que sólo los indígenas que "viven como indígenas" y entre indígenas pueden quedar exentos de cumplir con esta obligación.)

64 "Many Indians see sacred lands as integral to their very identity, and individual Indians are not the only ones becoming more active about Indian issues: the federal government has also begun to address their concerns. Despite the lack of Supreme Court recognition of off-reservation religious rights, Congress has passed legislation that recognizes the land-based nature of Indian religious traditions and makes a priority of Indian privacy and access to sacred sites". Robert Retherford, A Local Development Agreement on Access to Sacred Lands, 75 U. Colo. L. Rev. 963, 981 (2004), pág. 1.

6542 U.S.C. $\S 1996$ (2000)

6616 U.S.C. $\S \S 470$ to $470 \mathrm{x}-6(2000)$

6725 U.S.C. $\S \S 3001-3013,18$ U.S.C. $\S 1170$ (2000)

68 A Local Development Agreement, ibid.

69 Julie-Ann Tomiak and Donna Patrick, Transnational Migration and Indigeneity in Canada: A Case Study of Urban Inuit, en Maximilian C. Forte (ed.) Indigenous Cosmopolitans, Peter Lang, Publishing, New York, 2010.

70 Jack Forbes, The Urban Tradition Among Native Americans, pág. 1 (traducción del autor). Específicamente en relación con el contexto estadounidense señala David Beck, "American Indians lived in urban communities in the Americas for hundreds of years previous to Columbus's arrival here. The largest ancient urban center in what is now the United States was Cahokia, located a few miles from present-day St. Louis on the Illinois side of the border. And American Indians have lived in or near Euramerican and American cities since the earliest establishment of such places. Early Euramerican frontier towns on occasion held more people of mixed Indian and white blood than whites. Many American cities have had a continuous, though small, American Indian presence throughout their history. But urban Indian populations in the United States remained minute until after World War II". David R. M. Beck, Developing a Voice: The Evolution of SelfDetermination in an Urban Indian Community, Wicazo Sa Review, Vol. 17, $\mathrm{N}^{\circ}$. 2, Sovereignty and Governance, II (Autumn, 2002), pág. 119. Véase también, Jack Forbes, The Urban Tradition Among Native Americans, American Indian Culture and Research Journal $22 \mathrm{~N}^{\circ} 415-41,1998$.

71 Susan Lobo y Kart Peters, Introduction, The Urban Tradition Among Native Americans, American Indian Culture and Research Journal $22 \mathrm{~N}^{\circ} .415-41,1998$, pág. 1.

72 Mercedes López Rodríguez, Los resguardos muiscas y raizales de la sabana de Bogotá: espacios sociales de construcción de la memoria, en Ana María Gómez Londoño (ed.), Muiscas: representaciones, cartografías y etnopolíticas de la memoria, Editorial Pontificia Universidad Javeriana, Bogotá, 2005. 
73 Esto no quiere decir que todos los intereses de los indígenas tradicionales urbanos deban merecer un reconocimiento jurídico. Únicamente quiere decir que la alianza entre el liberalismo multicultural y el modelo indigenista oscurece su existencia. Por tanto, no permite describir precisamente a estas comunidades ni examinar cuáles de sus reclamos deben ser recogidos por el derecho.

74 Denver Indian Family Resource Center, Circle of Care: Keeping the Circle Whole, Adult Community Survey Data Results, April 2007, pág. 9, en http://difrc.org/DIFRCCoCadultsurvey-B\%20(2).doc)

75 Ibid, pág. 4

76 Ibid, pág. 9

77 Ibid, pág. 11

78 "Thus city organizations are ideally intertribal, whether general or for special skills and interests like dancing, photography, basketball, and the arts; for youth, educational, and recreational activities; or for problems like alcoholism; or welfare programs". Sol Tax, The Impact of Urbanization on American Indians, Annals of the American Academy of Political and Social Science, Vol. 436, American Indians Today (Mar., 1978), págs. 126 y 127.

79 "Self-determination" is in the narrow sense a term with legal implications in which the federal government recognizes the authority of tribes to govern themselves under the political and judicial definitions of limited sovereignty. In a larger sense, self-determination means the ability of a people to determine the direction of their own society and community in political, economic, social, and spiritual arenas. In this article, in relation to an urban Indian community, it means that com-munity's ability to define itself and its needs and its ability to advocate for itself in the larger society under its own terms. It implies the development of a voice through which all of these things can be done. Indians in cities lack the legal protections available to tribes and so have had to develop their own means of self-advocacy. Often urban Indian leaders have done this through the organizations they developed to address specific community concerns. Through these organizations, Indians have created dynamic urban communities in which the focus of leadership is generally advocacy on behalf of those community members in need. The history of such organizations dates back to the early decades of the twentieth century, predating the relocation era of the 1950s to 1970s. In the latter half of the century, their numbers and activities increased dramatically. David R. M. Beck, Developing a Voice: The Evolution of Self-Determination in an Urban Indian Community, Wicazo Sa Review, Vol. 17, No. 2, Sovereignty and Governance, II (Autumn, 2002), pp. $117-118$

80 Is Urban a person or a Place? Characteristics of Urban Indian Country, ibid., pags 3 y 4 (refiriéndose a las organizaciones indígenas de la Bahía de San Francisco, en particular, pero reconociendo que son características típicas de las organizaciones indígenas en los Estados Unidos).

81 Informe de la Comisión de Verdad Histórica y Nuevo Trato, 2003 , Volumen III Tomo I, Informes finales de los grupos de trabajo Grupo de Trabajo de Indígenas Urbanos, Indígenas en la ciudad: Sueños y Realidades para un Nuevo Trato, pág. http://biblioteca.serindigena.org/libros_digitales/ cvhynt/v_iii/t_i/pueblos/v3_t1_informe_indigenas_urbanos-2_.html. En este mismo texto agregan los indígenas Mapuche, "Los indígenas urbanos somos parte integrante de los pueblos indígenas de Chile, poseedores de la identidad propia de cada pueblo con todos los elementos culturales que la definen y que por distintas razones históricas nos encontramos ocupando estos territorios (macro región central) que es territorio Pikunche". "Debido a la interacción en los ámbitos de la cultura, la economía, la política desarrollada en la ciudad, hemos ido creando ciertas particularidades que nos diferencian de nuestros hermanos de las comunidades originarias, sin embargo mantenemos la cosmovisión ancestral como fundamento esencial de vida“."Sin duda, como individuos no estamos cultural ni ideológicamente tan puros, porque de una u otra forma estamos influenciados por las ideologías, las formas de pensar, las formas de vida dominantes existentes en la sociedad moderna. Considerando que la cultura es dinámica, que se va nutriendo y transformando por la acción humana, es indudable que nosotros estamos dando origen a nuevas expresiones culturales, aún no definidas del todo, conservando sus elementos ancestrales tales como: cosmovisión, idioma, espiritualidad e incorporando los elementos que la rodean". "Los indígenas urbanos tenemos respecto de los indígenas que viven en comunidades rurales, una forma de vida distinta, que incide en la forma de ver los 
fenómenos sociales, económicos, políticos y culturales porque estamos recibiendo con mayor intensidad los elementos de la gran ciudad. Sin embargo, esto no implica que la cosmovisión, la filosofía, la identidad, la cultura de nuestros pueblos se estén perdiendo; al contrario, ellas se mantienen puras y fuertes en sus entornos, aún más, son nuestras fuentes de inspiración y fortaleza espiritual. Por ello, nuestra lucha debe considerar la mantención y potenciación de los elementos culturales esenciales de nuestros respectivos pueblos que los hacen originales, potentes y perdurables en el tiempo. Los indígenas urbanos somos individuos esencialmente biculturales, multiculturales porque hemos desarrollado esencialmente dos formas de pensar y actuar que nos permite llevar una vida más soportable en la ciudad; la cabeza indígena en la ciudad -como decía un Kimche debe desarrollar dos partes: una parte indígena para mantener la sabiduría, la fuerza ancestral y la comunicación con su gente; la otra parte para saber entender el pensamiento moderno (winka) y, de esta manera, actuar en la ciudad que permita desarrollar la vida en condiciones diferentes a la de su origen.”

82 No argumento que los sistemas jurídicos de los Estados en donde habitan los indígenas metropolitanos deban reconocer necesariamente derechos diferenciados a estas comunidades. Argumento que su realidad debe ser examinada una vez se hagan explícitos los límites de las categorías conceptuales con las que usualmente se describen a las comunidades indígenas. Los derechos diferenciados, si alguno, que deban ser reconocidos a estas comunidades deben ser una consecuencia de un análisis juicioso de sus intereses y características. Del mismo modo debe tenerse en cuenta en este análisis las relaciones entre las comunidades indígenas metropolitanas particulares y el Estado al que pertenecen.

Daniel Bonilla Maldonado 
